\title{
Metabolomic analysis reveals the interaction of primary and secondary metabolism in white, pale green, and green pak choi (Brassica rapa subsp. chinensis)
}

Hyeon Ji Yeo ${ }^{1+}$, Seung-A Baek ${ }^{2+}$, Ramaraj Sathasivam ${ }^{1+}{ }^{1}$, Jae Kwang Kim ${ }^{2 *}$ and Sang Un Park ${ }^{1,3^{*}}$ (0)

\begin{abstract}
This study aimed to comprehensively analyze primary and secondary metabolites of three different-colored (white, pale green, and green) pak choi cultivars (Brassica rapa subsp. chinensis) using gas chromatography attached with time-of-flight mass spectrometry (GC-TOFMS) and high-performance liquid chromatography (HPLC). In total, 53 primary metabolites were identified and subjected to partial least-squares discriminant analysis. The result revealed a significant difference in the primary and secondary metabolites between the three pak choi cultivars. In addition, 49 hydrophilic metabolites were detected in different cultivars. Total phenolic and glucosinolate contents were highest in the pale green and green cultivars, respectively, whereas total carotenoid and chlorophyll contents were highest in the white cultivar. Superoxide dismutase activity, 2,2-diphenyl-1-picrylhydraz scavenging, and reducing power were slightly increased in the white, pale green, and green cultivars, respectively. In addition, a negative correlation between pigments and phenylpropanoids was discovered by metabolite correlation analysis. This approach will provide useful information for the development of strategies to enhance the biosynthesis of phenolics, glucosinolates, carotenoids, and chlorophyll, and to improve antioxidant activity in pak choi cultivars. In addition, this study supports the use of HPLC and GC-TOFMS-based metabolite profiling to explore differences in pak choi cultivars.
\end{abstract}

Keywords: Brassica rapa subsp. chinensis, Pak choi, Primary metabolite, Secondary metabolite, Carotenoid, Glucosinolate, Phenolics

\section{Introduction}

Plants can produce numerous types of metabolites, which play important roles in cell maintenance, development, and reproduction. Primary and secondary metabolites are produced in response to external factors and

\footnotetext{
*Correspondence: kjkpj@inu.ac.kr; supark@cnu.ac.kr

${ }^{\dagger}$ Hyeon Ji Yeo, Seung-A Baek and Ramaraj Sathasivam contributed equally to this work

1 Department of Crop Science, Chungnam National University, 99 Daehak-ro, Yuseong-gu, Daejeon 34134, Republic of Korea

${ }^{2}$ Division of Life Sciences and Bio-Resource and Environmental Center, Incheon National University, Yeonsu-gu, Incheon 22012, Republic of Korea

Full list of author information is available at the end of the article
}

endogenous signals. Among those secondary metabolites, the phenylpropanoid pathway is one of the most commonly studied [1]. The products of this pathway (flavonoids, lignans, and phenylpropanoids) have anti-allergenic, anti-bacterial, anti-inflammatory, antioxidant, and anti-viral activities, which are beneficial to human health [2-4]. In addition, these compounds have anti-cancer and anti-diabetic activities, and also help to prevent cardiovascular disease $[5,6]$.

Carotenoids are mainly $\mathrm{C}_{40}$ terpenoids and are an important group of secondary metabolites derived from the isoprenoid pathway. More than 600 naturally occurring pigments have been identified; yellow xanthophylls, orange carotene, and various other red pigments are 
synthesized and stored in the plastids of plants and play a vital role in several physiological processes. For example, carotenoids have important roles in chloroplast biogenesis by preventing photoinhibition during photosynthesis. In addition, they provide coloration to the fruit and flowers, which helps to attract pollinators and disperse seeds. Carotenoids provide a wide range of benefits to plants, algae, and humans [7-10]. Chlorophyll and its derivatives have been used as a traditional medicine in the past decade, and have various therapeutic properties, such as wound healing, and anti-inflammatory, and internal deodorant effects. Recent studies on chlorophyll have focused on its activities as an anti-carcinogen, anti-mutagen, and photosensitizer in photodynamic therapy [11].

Glucosinolates are a large group of secondary metabolites synthesized by plants, which contain nitrogen- and sulfur-containing groups and are mainly found in species of the Brassicaceae family [12]. Glucosinolates are relatively stable before being hydrolyzed into different types of biologically active products, which are catalyzed by myrosinases [13]. Glucosinolates and their breakdown products have various biological functions and provide benefits to human health and nutrition, including protection from cancer and cardiovascular diseases, as well as a plant defense against pathogens and herbivores [12, 14]. Therefore, glucosinolates have been examined for their role in human diet and animal feed consumption, as well as in plant defense systems.

During plant cellular metabolic processes as a normal product, the reactive oxygen species (ROS) are produced [15]. An increased level of ROS leads to various diseases such as allergies, cancer, respiratory, digestive, and neurodegenerative diseases [16]. Several studies have been reported that plants are considered to have natural antioxidant properties due to the presence of various secondary metabolites [15]. Hence, the intake of plant-derived antioxidants will reduce the damage caused by oxidative stress and protect humans from various diseases [17].

Recently, studies have been performed using model plants such as Arabidopsis thaliana, Solanum lycopersicum, and Nicotiana tabacum, whereas only a few studies have focused on leafy vegetables, which form part of the human diet [18-21]. Here, we investigated the profile of primary and secondary metabolites in white, pale green, and green pak choi. Pak choi (Brassica rapa subsp. chinensis) is a green leafy vegetable, also called Chinese cabbage. It is an important leafy vegetable cultivated widely in southern China, Southeast Asia, Northern Europe, and North America [22]. Pak choi contains numerous compounds with health benefits, such as plant secondary metabolites (carotenoids and chlorophylls), phenolic compounds (flavonoids, glucosinolates, kaempferol, isorhamnetin, quercetin, and hydroxycinnamic acid derivatives), vitamins, and minerals [23-26]. For these reasons, pak choi consumption is increasing in daily life. Zhang et al. [22] analyzed the anthocyanin content in purple pak choi (Brassica rapa var. chinensis), and Jeon et al. [27] compared the metabolic profile of green and purple pak choi cultivars (B. rapa subsp. chinensis) by gas chromatography attached with time-of-flight mass spectrometry (GC-TOFMS) and high-performance liquid chromatography (HPLC) analysis. However, although is an economically important crop, its metabolic profile and antioxidant activity remain unclear. In addition, analysis of the relationship between metabolites was rare.

In the present study, we evaluated the content and composition of phenylpropanoids, carotenoid, chlorophyll, and glucosinolates in white, pale green, and green pak choi cultivars using a GC-TOF-MS and HPLC system. The antioxidant activity of pak choi cultivars was also evaluated. In addition, we analyzed the metabolic profiles data using multivariate analysis tools. Understanding the comprehensive metabolic profile data and the relationship among metabolites might be helpful to improve the nutritional content and quality of pak choi cultivars.

\section{Materials and methods Plant growth}

Seeds of pak choi (Brassica rapa subsp. chinensis) were purchased from Asia Seed Co., Ltd (Seoul, Korea). Three types of pak choi (white, green, and pale green) were grown at an experimental farm in Chungnam National University, Daejeon, Korea. Three biological replicates were grown for each cultivar. The pak choi plants were harvested after 85 days. All harvested samples were frozen immediately in liquid nitrogen, subsequently stored at $-80{ }^{\circ} \mathrm{C}$, and lyophilized for metabolic profiling and antioxidant analysis. All compound analyses were performed in biological triplicates.

\section{GC-TOFMS analysis}

Hydrophilic metabolites were extracted based on the procedure described by Park et al. [28], with slight modification. Ten-milligrams of fine powder of the three pak choi cultivars were weighed and mixed with $1 \mathrm{~mL}$ of water:methanol:chloroform (1:2.5:1, v/v), and then $60 \mu \mathrm{L}$ of $0.2 \mathrm{~g} / \mathrm{L}$ adonitol (internal standard, IS) was added. The extraction was performed in a compact thermomixer at a mixing frequency of $1200 \mathrm{rpm}$ at $37^{\circ} \mathrm{C}$ for $30 \mathrm{~min}$. Then, the mixture was centrifuged at $10,000 \mathrm{rpm}$ for $5 \mathrm{~min}$, the supernatant $(800 \mu \mathrm{L})$ containing the polar phase was transferred into a clean $2.0 \mathrm{~mL}$ microcentrifuge tube, and $400 \mu \mathrm{L}$ of sterile deionized water was added. The mixture was centrifuged at 10,000 rpm for $5 \mathrm{~min}$ and the methanol:water phase containing polar metabolites 
was separated in a centrifugal concentrator (VS-802F, Vision, Daejeon, Korea) for $3 \mathrm{~h}$, and the rest of the material was lyophilized using a freeze dryer (MCFD8512, ilShin Bio-Base Co., Ltd, Dongducheon-si, Korea) for $16 \mathrm{~h}$. After lyophilization, the residues were subjected to a two-step process; methoxime derivatization and trimethylsilyl etherification. Methoxyamine hydrochloride in pyridine $(80 \mu \mathrm{L}, 20 \mathrm{~g} / \mathrm{L})$ was added to the vial and shaken at $1200 \mathrm{rpm}$ for $90 \mathrm{~min}$ at $30{ }^{\circ} \mathrm{C}$. Then, the sample was mixed with $80 \mu \mathrm{L}$ of $N$-methyl- $N$-(trimethylsilyl) trifluoroacetamide, and shaken at $1200 \mathrm{rpm}$ for $30 \mathrm{~min}$ at $37{ }^{\circ} \mathrm{C}$. The primary metabolites were separated by gas chromatography; the operating condition, system, flow rate, and gradient program were similar to those described by Park et al. [28]. The metabolites were identified using an in house library. Relative quantification was calculated from peak area ratios relative to the peak area of IS.

\section{Extraction of phenolic compound and HPLC analysis}

Phenylpropanoid compounds were extracted and analyzed following the protocol described by Park et al. [9]. A total of $100 \mathrm{mg}$ of each fine powder sample was mixed with $3 \mathrm{~mL}$ of $80 \%$ aqueous $\mathrm{MeOH}$ solution. Then, the mixture was vortexed for $1 \mathrm{~min}$ and sonicated at $37{ }^{\circ} \mathrm{C}$ for $1 \mathrm{~h}$. The mixture was centrifuged at $10,000 \mathrm{rpm}$ for $15 \mathrm{~min}$ at $4{ }^{\circ} \mathrm{C}$. The supernatants were collected and filter-sterilized through a $0.45 \mu \mathrm{m}$ PTFE syringe filter (Millipore, Bedford, MA, USA) into amber glass screw thread vials (Thermo Fisher Scientific, USA). The separation of phenylpropanoid compound was done by using a $\mathrm{C}_{18}$ column $(250 \times 4.6 \mathrm{~mm}, 5 \mu \mathrm{m})$ at $30{ }^{\circ} \mathrm{C}$ using an Agilent Technologies 1200 series HPLC system (Palo Alto, CA, USA) at $280 \mathrm{~nm}$. The mobile phase consisted of $\mathrm{MeOH} /$ water/acetic acid $(5: 92.5: 2.5, \mathrm{v} / \mathrm{v} / \mathrm{v})$ (solvent A) and $\mathrm{MeOH} /$ water/acetic acid $(95: 2.5: 2.5, \mathrm{v} / \mathrm{v} / \mathrm{v}$ ) (solvent B) with the flow rate of $1.0 \mathrm{~mL} / \mathrm{min}$, and the volume of injection was $20 \mu \mathrm{L}$. The gradient program as follows; $0 \%$ solvent B; $0-80 \%$ solvent B, $48 \mathrm{~min} ; 0 \%$ solvent $\mathrm{B}, 10 \mathrm{~min}$. Each phenolic were identified based on the retention time and results of spiking tests. The phenolic content of each sample was quantified with reference to a corresponding calibration curve.

\section{Extraction of carotenoid and HPLC analysis}

Carotenoid extraction and HPLC analysis were performed as described by Park et al. [9]. Carotenoids were extracted from $10 \mathrm{mg}$ of each fine powdered samples, placed in $15 \mathrm{~mL}$ conical tubes, and mixed with $3 \mathrm{~mL}$ of $0.1 \%,(\mathrm{w} / \mathrm{v})$ ascorbic acid/ethanol. The mixture was vortexed for $20 \mathrm{~s}$ and then incubated at $85{ }^{\circ} \mathrm{C}$ for $5 \mathrm{~min}$ in a water bath. For saponification, $120 \mu \mathrm{L}$ of $80 \%(w / v)$ potassium hydroxide was added to the mixture to remove any potentially interfering oils. After incubation, the samples were placed immediately on ice for $5 \mathrm{~min}$ to terminate the reaction, and then $100 \mu \mathrm{L}$ of $25 \mathrm{ppm}$ internal standard $\beta$-apo- 8 '-carotenal was added to the samples. Next, $1.5 \mathrm{~mL}$ of ice-cold distilled water and $1.5 \mathrm{~mL}$ of hexane were added to the above mixture, which was centrifuged at $1,200 \mathrm{rpm}$ for $5 \mathrm{~min}$ at $4{ }^{\circ} \mathrm{C}$. The extraction procedure was repeated twice. After centrifugation, the supernatant was collected, dried under nitrogen gas at room temperature, and $250 \mu \mathrm{L}$ of dichloromethane/ methanol 50:50 (v/v) was added to the dried samples. These mixtures were filtered using a $0.50 \mu \mathrm{m}$ PTFE filter (Advantec, Tokyo, Japan) into amber glass screw thread vials (Thermo Fisher Scientific, USA). Twenty microliter of the sample was separated using Agilent 1100 series HPLC (Agilent, Massy, France) equipped with YMC carotenoid S-3 $\mu \mathrm{m}$ column $(250 \times 4.6 \mathrm{~mm}$; YMC Co., Kyoto, Japan) and photodiode array detector. A 92:8 (v/v) methanol:water with $10 \mathrm{mM}$ ammonium acetate (solvent A) and methyl tert-butylether (solvent B) were used as gradient elution solvents. The gradient used for elution was as follows: $90 \%$ solvent $A / 10 \%$ solvent $B, 0$ min; $83 \%$ solvent $\mathrm{A} / 17 \%$ solvent $\mathrm{B}, 20 \mathrm{~min} ; 75 \%$ solvent $\mathrm{A} / 25 \%$ solvent $B, 29$ min; $30 \%$ solvent $A / 70 \%$ solvent $B, 35$ min; $30 \%$ solvent $A / 70 \%$ solvent $B, 40$ min; $25 \%$ solvent $A / 75 \%$ solvent B, 42 min; $90 \%$ solvent $A / 10 \%$ solvent B, 45 min; $90 \%$ solvent $\mathrm{A} / 10 \%$ solvent $\mathrm{B}, 55 \mathrm{~min}$. The solvent flow was $1.0 \mathrm{~mL} / \mathrm{min}$ and the column temperature was set at $40^{\circ} \mathrm{C}$. The chromatogram was obtained at $450 \mathrm{~nm}$. Each carotenoid was identified based on retention time and mass spectra compared with the standard. The mass spectra of each peak were compared with a previous study $\mathrm{Ha}$ et al. [29]. The carotenoid content of each sample was quantified with reference to a corresponding calibration curve.

\section{Analysis of chlorophyll contents}

Chlorophyll was extracted and analyzed as described by Park et al. [9], with slight modification. Chlorophyll was extracted from $10 \mathrm{mg}$ of freeze-dried pak choi samples which were mixed with $1 \mathrm{~mL}$ of methanol. The resulting mixture was vortexed for $30 \mathrm{~s}$ and then sonicated for $30 \mathrm{~min}$ at $70{ }^{\circ} \mathrm{C}$. Sonicated samples were subjected to centrifugation at $3000 \mathrm{rpm}$ for $10 \mathrm{~min}$ at $4{ }^{\circ} \mathrm{C}$. The resulting supernatant was filtered and measured at 666 and $653 \mathrm{~nm}$. The chlorophyll content was then estimated using a formula described previously Wellburn [30].

\section{Extraction of glucosinolate and HPLC analysis}

Glucosinolates were extracted and analyzed as described by Park et al. [9], with slight modification. Glucosinolates were extracted from $100 \mathrm{mg}$ of freeze-dried pak choi samples, which was mixed with $4.5 \mathrm{~mL}$ of boiling $70 \%$ (v/v) methanol and incubated in a water bath at $70{ }^{\circ} \mathrm{C}$ for 
$5 \mathrm{~min}$. Then, the mixture was centrifuged at $14,000 \mathrm{rpm}$ for $10 \mathrm{~min}$ at $4{ }^{\circ} \mathrm{C}$. The supernatant was passed through a mini-column containing diethylaminoethanol (DEAE) Sephadex A-25 (GE Healthcare, Uppsala, Sweden) and rinsed with $3 \mathrm{~mL}$ of sterile deionized water. For desulfation, the elute was mixed with $75 \mu \mathrm{L}$ of purified arylsulfatase and incubated overnight at room temperature. The next day, samples were eluted with $0.5 \mathrm{~mL}$ (X3) of ultrapure water into a clean $2.0 \mathrm{~mL}$ microcentrifuge tube and filtered using a $0.22 \mu \mathrm{m}$ PTFE syringe filters (Sterlitech Corp., Kent, WA, USA) into amber glass screw thread vials (Thermo Fisher Scientific, USA). The separation of glucosinolates was done by using a reversed-phase Inertsil ODS-3 column $(150 \times 3.0 \mathrm{~mm}, 3 \mu \mathrm{m})$ with an $\mathrm{E}$ type cartridge guard column $(10 \times 2.0 \mathrm{~mm}, 5 \mu \mathrm{m})$ at $40^{\circ} \mathrm{C}$ using an Agilent Technologies 1200 series HPLC system (Palo Alto, CA, USA) at $227 \mathrm{~nm}$. The mobile phase consisted of ultrapure water (solvent $\mathrm{A}$ ) and acetonitrile (solvent B) with the flow rate was $1 \mathrm{~mL} / \mathrm{min}$. The gradient programs were as follows (40 $\mathrm{min}$ in total); $7-24 \%$ solvent B, 18 min; $24 \%$ solvent B, 14 min; $7 \%$ solvent B, $32.1 \mathrm{~min}$; and $7 \%$ solvent B, $8 \mathrm{~min}$. Each glucosinolate was identified based on their HPLC peak area ratios and quantified based on the retention time, peak areas, and response factor with reference to a desulfo-sinigrin (Sigma-Aldrich Co., Ltd., St. Louis, MO, USA) external standard.

\section{Superoxide dismutase (SOD) activity}

The SOD activity of pak choi cultivar extracts was determined based on the reduction of nitroblue tetrazolium (NBT), as described by Park et al. [15]. A sample of $50-250 \mu \mathrm{L}$ of the methanol extract solution was mixed in a test tube with $0.2 \mu \mathrm{L}$ of $0.1 \mathrm{mM}$ ethylenediaminetetraacetic acid (EDTA) solution. Then, $100 \mu \mathrm{L}$ of $24 \mathrm{mM} \mathrm{NBT}$ and $1000 \mu \mathrm{L}$ of distilled water was added. The reaction was initiated by adding $\sim 0.1 \mathrm{~mL}$ of hydroxylamine hydrochloride $(1 \mathrm{mM})$. Samples were mixed gently and incubated at $25^{\circ} \mathrm{C}$ for $20 \mathrm{~min}$. Reduction of NBT was determined by measuring the absorbance at $560 \mathrm{~nm}$ using a UV spectrophotometer (Model UV-1800, Shimadzu corp., Japan) against an appropriate blank solution (sterile deionized water). Ascorbic acid was used as a positive control. SOD activity was estimated according to the formula described by Park et al. [15]. All analyses were performed using three biological replicates.

\section{Reducing power assay}

The reducing power of the methanol extracts of pak choi cultivars was evaluated as described by Park et al. [15]. Initially, we prepared a $200 \mathrm{mM}$ phosphate buffer solution ( $\mathrm{pH}$ 6.6). The reaction mixture consisted of $2.5 \mathrm{~mL}$ of $1 \%$ potassium ferricyanide and $50-250 \mu \mathrm{L}$ methanol extract solution, to which $2.5 \mathrm{~mL}$ aliquots of phosphate buffer were added. Then, the reaction mixture was incubated at $50{ }^{\circ} \mathrm{C}$ for $20 \mathrm{~min}$ and centrifuged at $3000 \mathrm{rpm}$ for $15 \mathrm{~min}$. After centrifugation, the supernatant $(\sim 2.5 \mathrm{~mL})$ was transferred into a new $15 \mathrm{~mL}$ Falcon tube and mixed with $2.5 \mathrm{~mL}$ of $10 \%$ trichloroacetic acid (TCA). Sterile deionized water $(2.5 \mathrm{~mL})$ and $0.5 \mathrm{~mL}$ of $1 \%$ ferric chloride were added to this mixture. Ascorbic acid was used as a positive control. The absorbance of the reaction mixture was measured at $700 \mathrm{~nm}$; an increase in absorbance at $700 \mathrm{~nm}$ indicated an increase in the reducing power of each sample. All analyzes were performed using three biological replicates.

\section{2-diphenyl-1-picrylhydrazyl (DPPH) scavenging assay}

A pak choi DPPH scavenging assay was performed as described by Jeon et al. [31]. We prepared a $0.15 \%$ icecold methanol DPPH solution. The reaction mixture contained $4 \mathrm{~mL}$ of methanol and different concentrations of extracts $(20-100 \mu \mathrm{g} / \mathrm{mL}$ in $1 \mathrm{~mL})$. DPPH solution $(0.2 \mathrm{~mL})$ was added to the mixture, which was then incubated for $30 \mathrm{~min}$ in the dark at room temperature before the absorbance was measured at $515 \mathrm{~nm}$. Ascorbic acid was used as a positive control. DPPH radical scavenging activity was estimated according to the formula described by Jeon et al. [31]. All analyzes were performed using three biological replicates.

\section{Statistical analysis}

The data obtained from metabolic profiling were scaled to unit variance (UV) and then principal component analysis (PCA) and partial least squares-discriminant analysis (PLS-DA) were implemented using SIMCA$\mathrm{P}+12.0$ software (Umetrics AB, Sweden). The PCA output provided an overview of the data, and the PLS-DA output was presented as a score plot to demonstrate the difference. All data were analyzed using IBM SPSS Statistics statistical software (version 24.0; IBM Corp, Armonk, NY, USA), and a Student's $t$-test was performed to determine significant differences and to illustrate the metabolite map. PathVisio 3.0.0 (https://pathvisio.github.io) was used to visualize metabolic pathways based on a modified Arabidopsis metabolic pathway downloaded from WikiPathways [AtMetExpress overview (Arabidopsis thaliana)]. Pearson's correlation analysis and hierarchical cluster analysis (HCA) were performed using MetaboAnalyst (https://www.metaboanalyst.ca/).

\section{Results}

Phenotypic variation between the three pak choi cultivars A non-heading leaf-type pak choi that produces large, succulent, and glossy green leaves with different colors of stalks was used. We classified pak choi as white, pale green, and green based on their stalk color (Fig. 1). The 


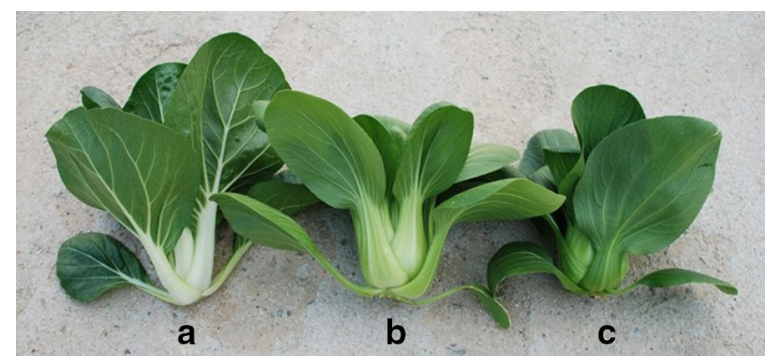

Fig. 1 Photographs of mature pak choi. a white, b pale green, and c green pak choi

dry weight of whole plant of white, pale green, and green pak choi cultivars are as follows $12.1 \pm 0.9,11.5 \pm 0.8$, $11.2 \pm 0.8 \mathrm{~g} / \mathrm{dw}$ (Additional file 1: Table S1).

\section{PCA and PLS-DA}

PCA was performed to visualize the comprehensive metabolic profiling data obtained from the GC-TOFMS and HPLC analysis. The score plot of PCA showed clear separation among the pak choi cultivars (Fig. 2a). The white cultivar was separated from pale green and green cultivar by the first component (principal component 1 ; PC1). The pale green and green cultivar were separated by PC2. The loading plot of PCA showed the relative level of metabolites in each cultivar (Fig. 2b). For example, the white cultivar had a relatively higher level of quercetin, kaempferol, and photosynthetic pigments than those in the pale green and green cultivar. The PLS-DA was suitable to identify the metabolites that explain the difference among the three cultivars. R2 value closer to 1.0 is desirable and it indicates the goodness of fit for the PLS-DA model. Q2 value indicates the goodness of the prediction model, and Q2 $>0.9$ indicates an excellent prediction model. The PLS-DA model of the pak choi showed good separation $(\mathrm{R} 2 \mathrm{Y}=0.980, \mathrm{Q} 2=0.937)$ (Fig. 3). A value higher than 1.0 of variable importance in the projection (VIP) represents influential for the PLS-DA model and it is indicated those metabolites differ among the samples. Totally 53 kinds of metabolites were showed higher than 1.0 VIP value (Fig. 4 and Additional file 1: Table S2). Among the 53 kinds of metabolites, shikimic acid, phenylalanine, and phenylpropanoids except for catechin hydrate, quercetin, kaempferol were included. It indicated that the content of the metabolites related to the phenylpropanoid pathway has highly differed among the three cultivars.

\section{Analysis of hydrophilic metabolites content}

Hydrophilic metabolic profiles of white, pale green, and green pak choi were determined using GC-TOFMS.
Forty-nine different hydrophilic metabolites were identified among the cultivars (Additional file 1: Fig. S1 and Table S3). Among these, 22 amino acids and amino acid derivatives were identified. The levels of leucine, proline, tyrosine, $\beta$-alanine, and 4 -amino butanoic acid were higher in white pak choi relative to the other cultivars. The levels of alanine, glycine, methionine, and tryptophan were higher in the green cultivar than in the white and pale green cultivars. Eleven organic acids, phosphoric acid, and urea were identified in the three pak choi cultivars. The levels of citric acid, pyruvic acid, and quinic acid were higher in the white pak choi relative to the pale green and green cultivars. In the pale green cultivar, the levels of fumaric acid and shikimic acid were higher compared with the other cultivars. The levels of succinic acid and phosphoric acid were higher in the green cultivar that in the other cultivars. The level of raffinose was the highest, and the level of arabinose was the lowest in the white cultivar. The levels of xylose, glyceric acid, and inositol were higher in pale green pak choi than in the other cultivars. The levels of threonic acid, fructose 6-phosphate, and glucose 6-phosphate were higher in the green cultivar compared with the other cultivars. The primary metabolite contents in pak choi varied among the three cultivars.

\section{Analysis of phenylpropanoid content}

HPLC analysis of white, pale green, and green pak choi revealed the presence of 9 main phenolic compounds, including catechin hydrate, chlorogenic acid, epicatechin, ferulic acid, kaempferol, $p$-coumaric acid, quercetin, rutin, and trans-cinnamic acid (Additional file 1: Fig. S2 and Table 1). Among the phenolic compounds $(\mu \mathrm{g} / \mathrm{g} \mathrm{dw})$, the total phenolic content was high in all cultivars, whereas the content of trans-cinnamic acid was low. In addition, the levels of most of the phenolic compounds were higher in the pale green followed by the green cultivar, and finally, the white cultivar. In the pale green cultivar, the contents of catechin hydrate, ferulic acid, $p$-coumaric acid, and trans-cinnamic acid were higher, whereas, in the green cultivar, the contents of chlorogenic acid, epicatechin, and rutin were higher. However, in the white cultivar, only two phenolic compounds (quercetin and kaempferol) were present at higher levels. Interestingly, epicatechin was present only in the pale green and green cultivars and was not detected in the white cultivar. The total phenolic compounds were found in the pale green cultivar $(799.88 \mu \mathrm{g} / \mathrm{g} \mathrm{dw})$, and were 2.21-and 1.00-fold higher than in the white and green cultivars, respectively. Similarly, the ferulic acid content in the pale green cultivar was 1.79- and 1.14-fold higher than that in the white and green cultivars, respectively. In the pale green and 


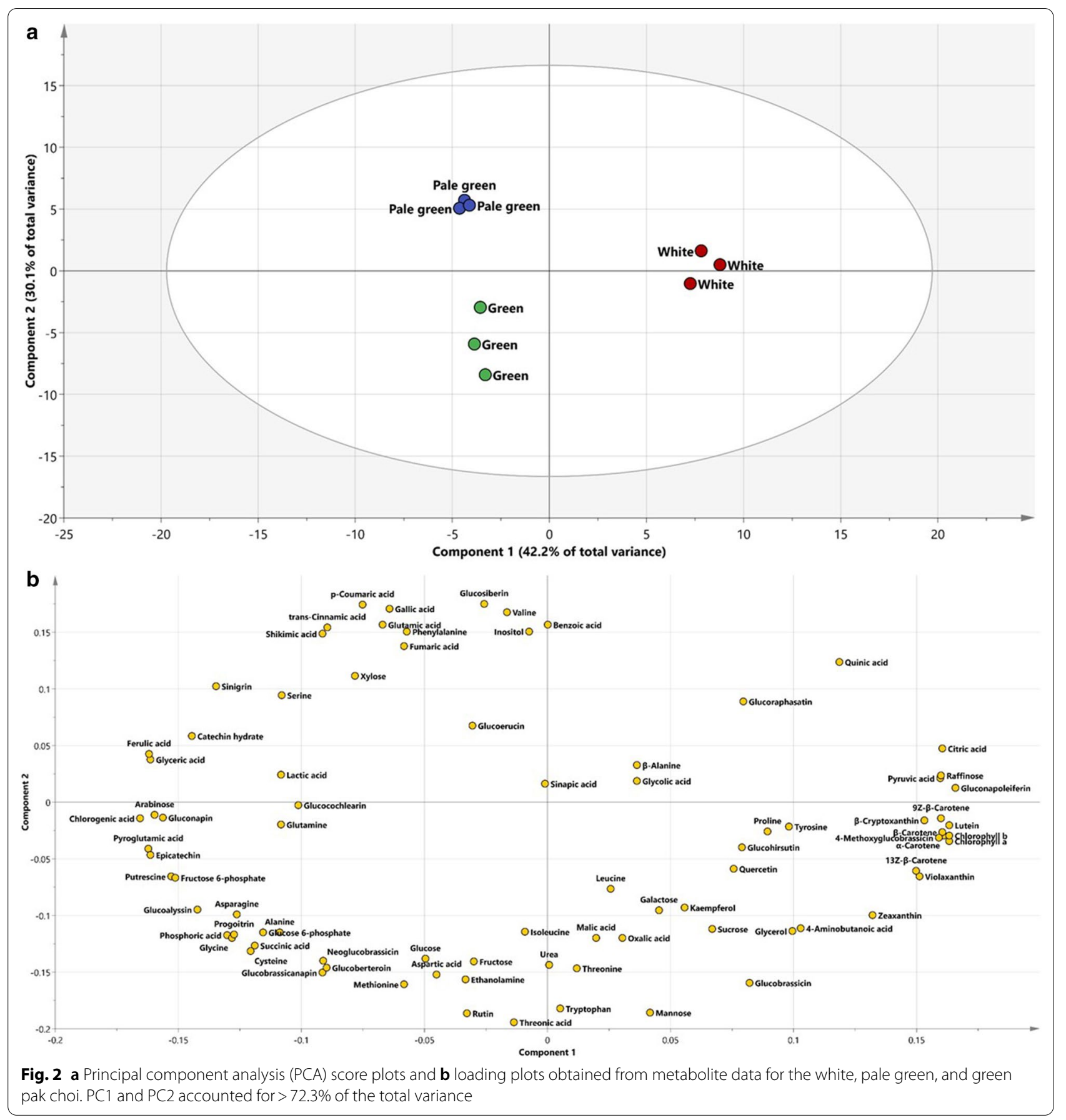

green cultivars, the levels of ferulic acid, chlorogenic acid, and $p$-coumaric acid were significantly higher than the levels of other phenolic compounds. Conversely, the levels of chlorogenic acid in the green and pale green cultivars were 4.52- and 4.65-fold higher than in the white cultivar. These results indicated, that among the different pak choi cultivars, the pale green cultivar contained the highest phenolic content.

\section{Analysis of carotenoid and chlorophyll}

HPLC analysis of the three pak choi cultivars revealed the presence of eight different carotenoids: 13Z- $\beta$ carotene, 9Z- $\beta$-carotene, lutein, violaxanthin, zeaxanthin, $\alpha$-carotene, $\beta$-carotene, and $\beta$-cryptoxanthin (Additional file 1: Fig. S3 and Table 2). The level of total carotenoids was significantly higher in the white cultivar compared with the pale green and green cultivars. 


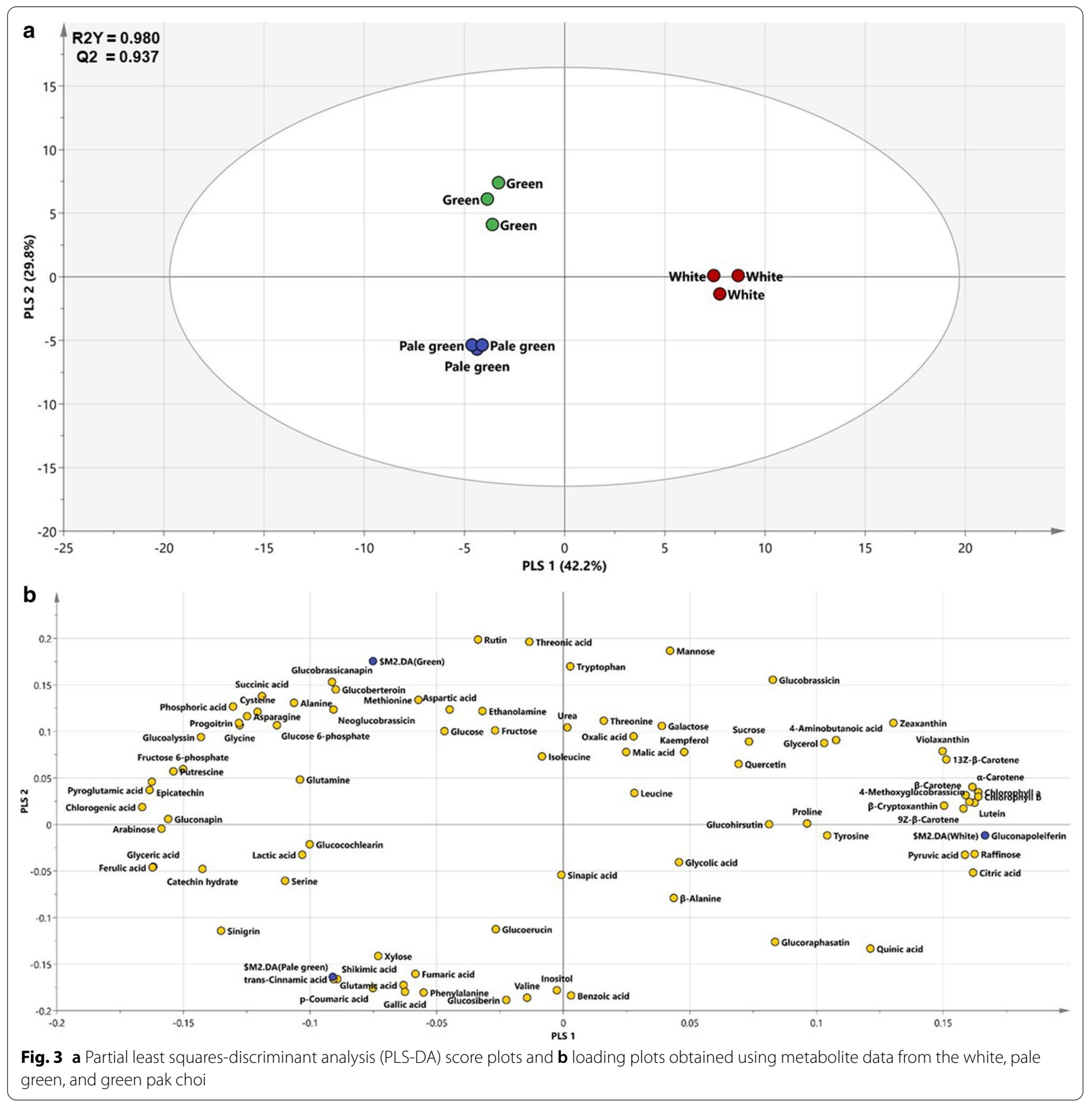

Specifically, the total carotenoid content in the white cultivar $(677.11 \mu \mathrm{g} / \mathrm{g} \mathrm{dw})$ was 2.49 - and 1.87-fold higher than that in the pale green $(271.7111 \mu \mathrm{g} / \mathrm{g} \mathrm{dw})$ and green cultivars (362.98 $11 \mu \mathrm{g} / \mathrm{g} \mathrm{dw})$, respectively. A similar result was obtained for individual carotenoids, with higher contents in the white cultivar compared with the pale green and green cultivators. In the white cultivar, the highest individual carotenoid contents were observed for $\beta$-carotene, lutein, 9Z- $\beta$-carotene, 13Z- $\beta$-carotene, zeaxanthin, $\alpha$-carotene, violaxanthin, and $\beta$-cryptoxanthin, which were found at levels 2.3-, 2.75-, 2.3-, 2.7-, 2.04-, 2.38-, 3.74-, and 2.04-fold higher than in the pale green cultivar. In the pale green cultivars, these were found at levels 1.77-, 2.07-, 1.92-, 1.58-, 1.24-, 1.75-, 2.23-, and 1.72 -fold higher than in the green cultivar, respectively. In all three pak choi cultivars, the levels of $\beta$-carotene, lutein, 9Z- $\beta$-carotene, and 13Z- $\beta$-carotene were significantly higher than the levels of other carotenoids. Interestingly, violaxanthin was only identified in the white and green cultivars, whereas it was not detected in the pale 


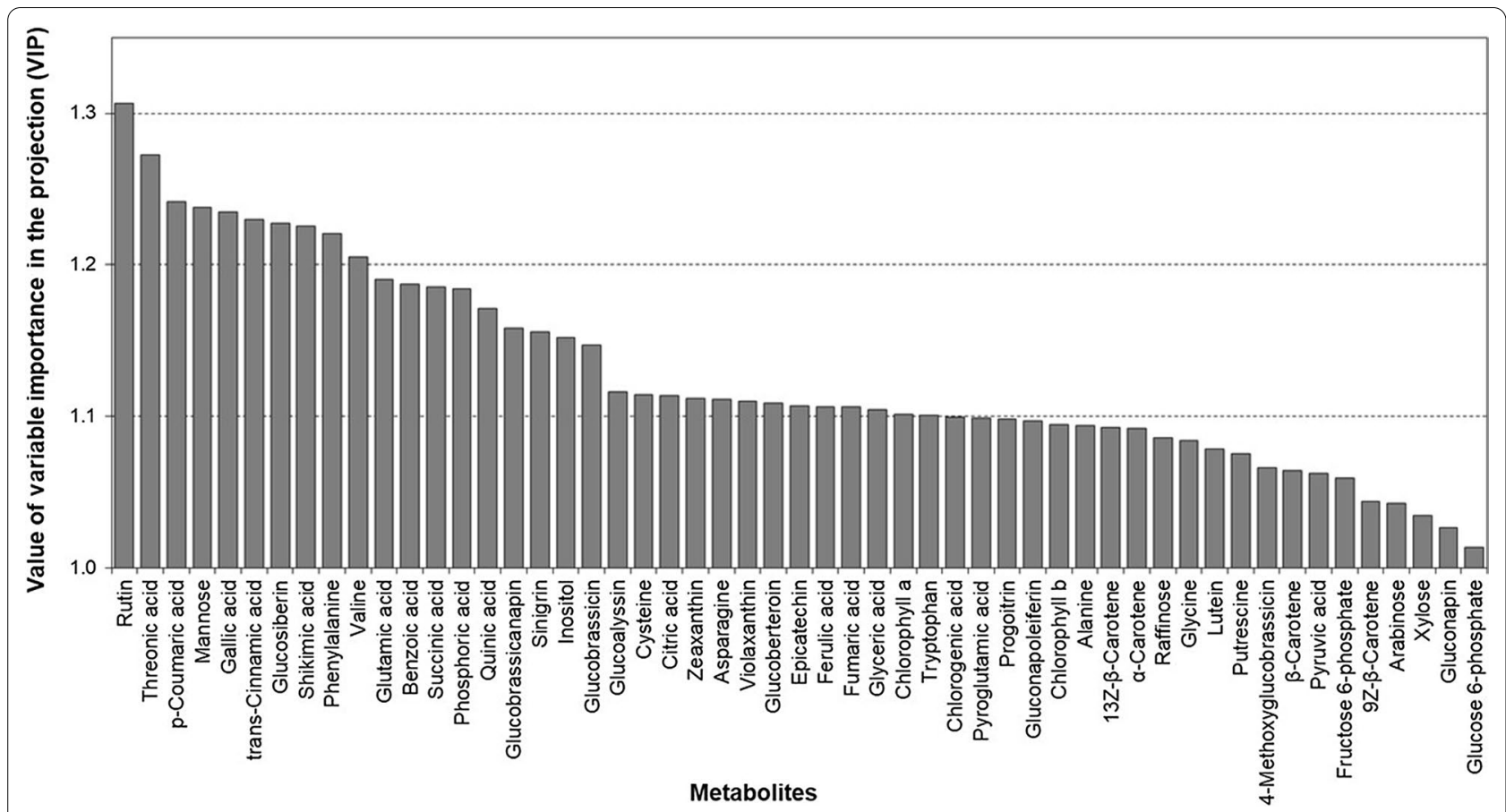

Fig. 4 Metabolites with higher variable importance in the projection (VIP) values are more influential for the sample separation. Metabolites with a VIP $>1.0$ are shown in the VIP plots

Table 1 Phenylpropanoid contents in white, pale green, and green pak choi

\begin{tabular}{llrr}
\hline Phenylpropanoid $\mathbf{( \mu g / g ~ d w )}$ & White & Pale green & Green \\
\hline Catechin & $8.06 \pm 2.18 \mathrm{c}$ & $15.21 \pm 1.13 \mathrm{a}$ & $12.87 \pm 2.25 \mathrm{~b}$ \\
Chlorogenic acid & $27.55 \pm 2.17 \mathrm{c}$ & $124.47 \pm 2.21 \mathrm{~b}$ & $128.33 \pm 4.93 \mathrm{a}$ \\
Epicatechin & $\mathrm{ND}$ & $138.13 \pm 2.71 \mathrm{~b}$ & $168.86 \pm 14.26 \mathrm{a}$ \\
p-coumaric acid & $42.10 \pm 0.94 \mathrm{~b}$ & $53.83 \pm 0.87 \mathrm{a}$ & $40.65 \pm 2.50 \mathrm{c}$ \\
Ferulic acid & $252.16 \pm 12.97 \mathrm{c}$ & $451.25 \pm 10.19 \mathrm{a}$ & $393.53 \pm 5.65 \mathrm{~b}$ \\
Rutin & $15.45 \pm 0.16 \mathrm{~b}$ & $7.75 \pm 0.24 \mathrm{c}$ & $36.04 \pm 0.90 \mathrm{a}$ \\
trans-cinnamic acid & $1.09 \pm 0.22 \mathrm{~b}$ & $2.60 \pm 0.16 \mathrm{a}$ & $1.11 \pm 0.12 \mathrm{~b}$ \\
Quercetin & $9.23 \pm 8.10 \mathrm{a}$ & $2.87 \pm 2.52 \mathrm{c}$ & $7.10 \pm 3.35 \mathrm{~b}$ \\
Kaempferol & $7.03 \pm 3.45 \mathrm{a}$ & $3.77 \pm 1.33 \mathrm{c}$ & $6.81 \pm 4.46 \mathrm{~b}$ \\
Total & $362.67 \pm 30.19 \mathrm{c}$ & $799.88 \pm 21.36 \mathrm{a}$ & $795.3 \pm 38.42 \mathrm{~b}$ \\
\hline
\end{tabular}

ND not detected. Mean values with different letters a-c denote a significant difference $(p<0.05$, ANOVA, Duncan's multiple range test (DMRT) within the column

green cultivar. These results indicate, that the levels of most carotenoids were higher in the white cultivar compared with the other two cultivars.

The total chlorophyll content was highest in the white cultivar $(6870 \mu \mathrm{g} / \mathrm{g} \mathrm{dw})$ followed by the green $(4020 \mu \mathrm{g} / \mathrm{g}$ $\mathrm{dw})$ and pale green $(3150 \mu \mathrm{g} / \mathrm{g} \mathrm{dw})$ cultivars. The total chlorophyll content in the white cultivar was 1.71- and 2.18-fold higher than that in the green and pale green cultivars, respectively (Table 3 ). The Chl $a$ content was also higher in the white cultivar $(4830 \mu \mathrm{g} / \mathrm{g} \mathrm{dw}) \mathrm{com}$ pared with the pale green $(2170 \mu \mathrm{g} / \mathrm{g} \mathrm{dw})$ and green
$(2810 \mu \mathrm{g} / \mathrm{g} \mathrm{dw})$ cultivars. A similar result was obtained for Chl $b$; the content in the white cultivar were 2.08- and 1.69 -fold higher than in pale green and green cultivars, respectively.

\section{Analysis of glucosinolate content}

HPLC analysis of the three pak choi cultivars revealed the presence of 13 glucosinolate compounds. There was a slight variation in the glucosinolate content of the three cultivars. The total glucosinolate level was highest in the green cultivar $(1647.18 \mu \mathrm{g} / \mathrm{g} \mathrm{dw})$ followed by the pale 
Table 2 Carotenoid contents in white, pale green, and green pak choi

\begin{tabular}{lclc}
\hline $\begin{array}{l}\text { Carotenoids } \\
(\boldsymbol{\mu} \mathbf{g} / \mathbf{g ~ d} \mathbf{~})\end{array}$ & White & Pale green & \multicolumn{1}{c}{ Green } \\
\hline Violaxanthin & $3.74 \pm 0.69 \mathrm{a}$ & $\mathrm{ND}$ & $1.68 \pm 0.20 \mathrm{~b}$ \\
Lutein & $269.97 \pm 30.47 \mathrm{a}$ & $98.15 \pm 6.80 \mathrm{c}$ & $130.17 \pm 13.25 \mathrm{~b}$ \\
Zeaxanthin & $13.21 \pm 1.59 \mathrm{a}$ & $6.49 \pm 0.63 \mathrm{c}$ & $10.65 \pm 1.01 \mathrm{~b}$ \\
$\beta$-cryptoxanthin & $3.00 \pm 0.62 \mathrm{a}$ & $1.47 \pm 0.22 \mathrm{c}$ & $1.74 \pm 0.11 \mathrm{~b}$ \\
13Z- $\beta$-carotene & $43.05 \pm 4.17 \mathrm{a}$ & $16.08 \pm 4.29 \mathrm{c}$ & $27.17 \pm 1.49 \mathrm{~b}$ \\
a-carotene & $4.87 \pm 0.27 \mathrm{a}$ & $2.05 \pm 0.15 \mathrm{~b}$ & $2.79 \pm 0.32 \mathrm{~b}$ \\
$\beta$-carotene & $282.87 \pm 38.79 \mathrm{a}$ & $123.01 \pm 5.69 \mathrm{c}$ & $159.37 \pm 12.52 \mathrm{~b}$ \\
9Z- $\beta$-carotene & $56.38 \pm 9.69 \mathrm{a}$ & $24.46 \pm 0.99 \mathrm{c}$ & $29.41 \pm 2.40 \mathrm{~b}$ \\
Total & $677.11 \pm 86.29 \mathrm{a}$ & $271.71 \pm 18.76 \mathrm{c}$ & $362.98 \pm 31.32 \mathrm{~b}$
\end{tabular}

$N D$ not detected. Mean values with different letters a-c denote a significant difference $(p<0.05$, ANOVA, DMRT) within the column

Table 3 Chlorophyll contents in white, pale green,
and green pak choi

\begin{tabular}{llll}
\hline Chlorophyll $(\boldsymbol{\mu g} / \mathbf{g ~ d w})$ & White & Pale green & Green \\
\hline Chlorophyll $a$ & $4830 \pm 0.18 \mathrm{a}$ & $2170 \pm 0.14 \mathrm{c}$ & $2810 \pm 0.10 \mathrm{~b}$ \\
Chlorophyll $b$ & $2040 \pm 0.11 \mathrm{a}$ & $980 \pm 0.07 \mathrm{c}$ & $1210 \pm 0.04 \mathrm{~b}$ \\
Total & $6870 \pm 0.29 \mathrm{a}$ & $3150 \pm 0.20 \mathrm{c}$ & $4020 \pm 0.14 \mathrm{~b}$
\end{tabular}

Mean values with different letters a-c denote a significant difference $(p<0.05$, ANOVA, DMRT) within the column

green $(1599.52 \mu \mathrm{g} / \mathrm{g} \mathrm{dw})$ and white $(356.89 \mu \mathrm{g} / \mathrm{g} \mathrm{dw}) \mathrm{cul}-$ tivars (Additional file 1: Fig. S4 and Table 4). Among the individual glucosinolates, the content of gluconapin was significantly higher than that of the other glucosinolates. Gluconapin content was significantly higher in the pale green $(1041.8 \mu \mathrm{g} / \mathrm{g} \mathrm{dw})$ and green $(1011.87 \mu \mathrm{g} / \mathrm{g} \mathrm{dw})$ cultivars compared with the white cultivar $(356.89 \mu \mathrm{g} / \mathrm{g}$ $\mathrm{dw})$. The glucobrassicin and neoglucobrassicin content were also slightly higher in all three cultivars. The sinigrin content was higher in the pale green $(1982.92 \mu \mathrm{g} / \mathrm{g}$ $\mathrm{dw})$ and green cultivar $(75.35 \mu \mathrm{g} / \mathrm{g} \mathrm{dw})$, whereas it was not detected in the white cultivar. Similarly, glucobrassicanapin was not detected in the white cultivar, whereas small amounts were detected in the pale green and green cultivars. Interestingly, gluconapoleiferin was only identified in the white cultivar. The level of 4-methoxyglucobrassicin was 2.27- and 1.83-fold higher in the white cultivar compared with the pale green and green cultivars, respectively. The contents of the other glucosinolates ranged from 1.64 to $12.42 \mu \mathrm{g} / \mathrm{g} \mathrm{dw}$ in the white cultivar. In the pale green cultivar, except for gluconapin and sinigrin, the content of glycoalyssin $(67.18 \mu \mathrm{g} / \mathrm{g} \mathrm{dw})$ was higher than that of the other glucosinolates (2.38$46.89 \mu \mathrm{g} / \mathrm{g} \mathrm{dw})$. In the green cultivar, the levels of progoitrin and glucoalyssin were 1.95- and 1.62-fold higher than in the pale green cultivar, respectively. The level of glucobrassicin in the white and green cultivars was 97.35 and $97.67 \mu \mathrm{g} / \mathrm{g} \mathrm{dw}$, which was 2.07 and 2.08-fold higher than the pale green cultivar, respectively. In addition, glucoerucin was not detectable in the green cultivar, whereas the content was slightly higher in the other two cultivars. The results showed that green pak choi contained the highest individual and total glucosinolate contents among the pak choi cultivars.

\section{In vitro antioxidant assays}

The SOD-like activity of the methanol extracts from the three pak choi cultivars (volumes ranged from 31.25

Table 4 Glucosinolate contents in white, pale green, and green pak choi

\begin{tabular}{llll}
\hline Glucosinolates $(\boldsymbol{\mu g} / \mathbf{g ~ d w})$ & White & Pale green & Green \\
\hline Progoitrin & $5.43 \pm 1.40 \mathrm{c}$ & $35.54 \pm 5.27 \mathrm{~b}$ & $69.32 \pm 20.39 \mathrm{a}$ \\
Sinigrin & $\mathrm{ND}$ & $198.92 \pm 26.42 \mathrm{a}$ & $75.35 \pm 16.60 \mathrm{~b}$ \\
Glucoalyssin & $10.55 \pm 0.50 \mathrm{c}$ & $67.18 \pm 7.41 \mathrm{~b}$ & $109.06 \pm 20.27 \mathrm{a}$ \\
Gluconapoleiferin & $12.42 \pm 0.93 \mathrm{a}$ & $\mathrm{ND}$ & $\mathrm{ND}$ \\
Gluconapin & $4.85 \pm 0.24 \mathrm{c}$ & $1041.8 \pm 68.51 \mathrm{a}$ & $1011.87 \pm 387.45 \mathrm{~b}$ \\
Glucoiberin & $10.58 \pm 3.32 \mathrm{~b}$ & $21.18 \pm 4.98 \mathrm{a}$ & $2.82 \pm 0.41 \mathrm{c}$ \\
Glucobrassicanapin & $\mathrm{ND}$ & $2.38 \pm 0.21 \mathrm{~b}$ & $14.02 \pm 5.13 \mathrm{a}$ \\
Glucoerucin & $2.56 \pm 0.77 \mathrm{~b}$ & $3.75 \pm 0.89 \mathrm{a}$ & $\mathrm{ND}$ \\
Glucoraphasatin & $6.49 \pm 0.78 \mathrm{a}$ & $5.87 \pm 0.89 \mathrm{~b}$ & $3.66 \pm 1.57 \mathrm{c}$ \\
Glucobrassicin & $97.35 \pm 6.03 \mathrm{a}$ & $46.89 \pm 7.74 \mathrm{~b}$ & $97.67 \pm 20.30 \mathrm{a}$ \\
4-Methoxyglucobrassicin & $94.87 \pm 1.97 \mathrm{a}$ & $41.83 \pm 3.75 \mathrm{c}$ & $51.93 \pm 12.25 \mathrm{~b}$ \\
Glucoberteroin & $3.39 \pm 1.21 \mathrm{c}$ & $9.31 \pm 1.11 \mathrm{~b}$ & $35.19 \pm 14.69 \mathrm{a}$ \\
Neoglucobrassicin & $106.75 \pm 3.21 \mathrm{c}$ & $124.86 \pm 7.68 \mathrm{~b}$ & $174.25 \pm 42.50 \mathrm{a}$ \\
Total & $356.89 \pm 10.96 \mathrm{c}$ & $1599.52 \pm 113.44 \mathrm{~b}$ & $1647.18 \pm 534.72 \mathrm{a}$ \\
\hline
\end{tabular}

ND not detected. Mean values with different letters a-c denote a significant difference $(p<0.05$, ANOVA, DMRT) within the column 
to $1000 \mu \mathrm{g} / \mathrm{mL}$ ) was slightly increased with increasing concentrations (Fig. 5a). At $31.25 \mu \mathrm{g} / \mathrm{mL}$, the scavenging activity of the ascorbic acid $(94.11 \pm 0.2 \%)$, whereas the methanolic extract of white, pale green, green cultivars were $90.84 \pm 0.1 \%, 91.7 \pm 0.1 \%$, and $91.27 \pm 0.1 \%$, respectively. Among the three different cultivars, the methanol extracts from white pak choi had higher activity $(93.34 \pm 0.1 \%)$ than the pale green and green cultivars at $1,000 \mu \mathrm{g} / \mathrm{mL}$. The reducing power of the pak choi

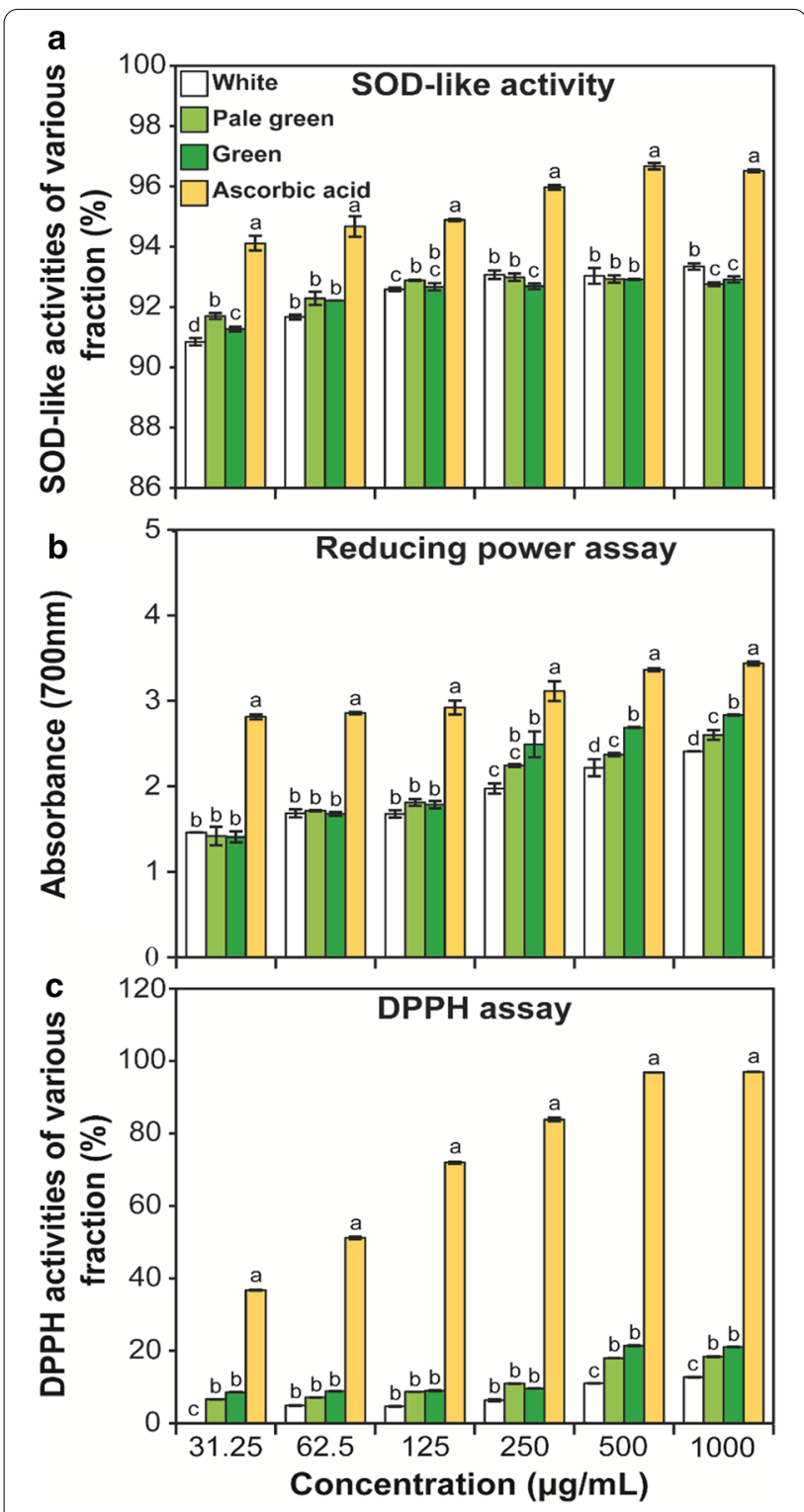

Fig. 5 Antioxidant activity of methanol extracts from three pak choi cultivars. a superoxide radical scavenging assay, b reducing power assay, and $\mathbf{c}$ DPPH radical scavenging assay. The means and standard deviation were calculated from three biological replicates. Mean values with a different letter a-e were significantly different $(p<0.05$, ANOVA, DMRT) extracts was also increased gradually with increasing concentrations. Notably, the green extracts presented the highest antioxidant activity among the cultivars tested at 250, 500, and $1,000 \mu \mathrm{g} / \mathrm{mL}$ (Fig. 5b). The DPPH free radical scavenging activity of different pak choi cultivar extracts was calculated at different concentrations (volumes ranged from 31.25 to $1000 \mu \mathrm{g} / \mathrm{mL}$ ). At most tested concentrations, DPPH activity was slightly increased in the green cultivar compared with the white and pale green cultivars. Methanolic extract from white, pale green, green cultivars had $12.70 \pm 0.1 \%, 18.39 \pm 0.1 \%$, and $21.07 \pm 0.1 \% \mathrm{DPPH}$ activity, respectively, at the $1,000 \mu \mathrm{g} /$ $\mathrm{mL}$ concentration, whereas the DPPH activity of ascorbic acid was $97.01 \pm 0.0 \%$. At the initial concentration $(31.25 \mu \mathrm{g} / \mathrm{mL})$, the white cultivar did not present any DPPH activity (Fig. 5c).

\section{Metabolic pathway map comparing primary and secondary metabolites}

Pathvisio software was used to compare the differences between the three pak choi cultivars based on the metabolite pathway [32]. The UV scaling data were input into the pathway and visualized as red or green colors per the scale bar (Fig. 6). Among the three cultivars, the levels of pyruvic acid and pigments were highest in the white cultivar, while the levels of glucose, fructose, glucose 6-phosphate, and fructose 6-phosphate were the lowest. In contrast, the levels of pyruvic acid and pigments were lower, and the levels of glucose, fructose, glucose 6-phosphate, and fructose 6-phosphate were higher in the pale green and green cultivars compared with the white cultivar. The levels of phenylalanine, trans-cinnamic acid, $p$-coumaric acid, ferulic acid, benzoic acid, chlorogenic acid, and gallic acid were higher in the pale green pak choi compared to the other cultivars. The level of the phenylalanine precursor, shikimic acid, was also highest in the pale green pak choi cultivar. However, the levels of flavonols (rutin, quercetin, and kaempferol) were lower in the pale green cultivar than in the other cultivars. The levels of flavonols (catechin and epicatechin) were higher in the pale green and green cultivar than in the white cultivar. The levels of methionine and tryptophan, which is used as a precursor of aromatic and indolic glucosinolate metabolism, respectively, were highest in the green cultivar. In the green cultivar, the levels of methionine and tryptophan were 2.28 - and 1.20-fold higher than in the white cultivar, in which their levels were 2.23- and 1.50fold higher than in the pale green cultivar, respectively (Additional file 1: Table S3).

\section{Metabolite-to-metabolite correlation}

A relation between metabolites has been analyzed using Pearson's correlation coefficient or other related similarity 


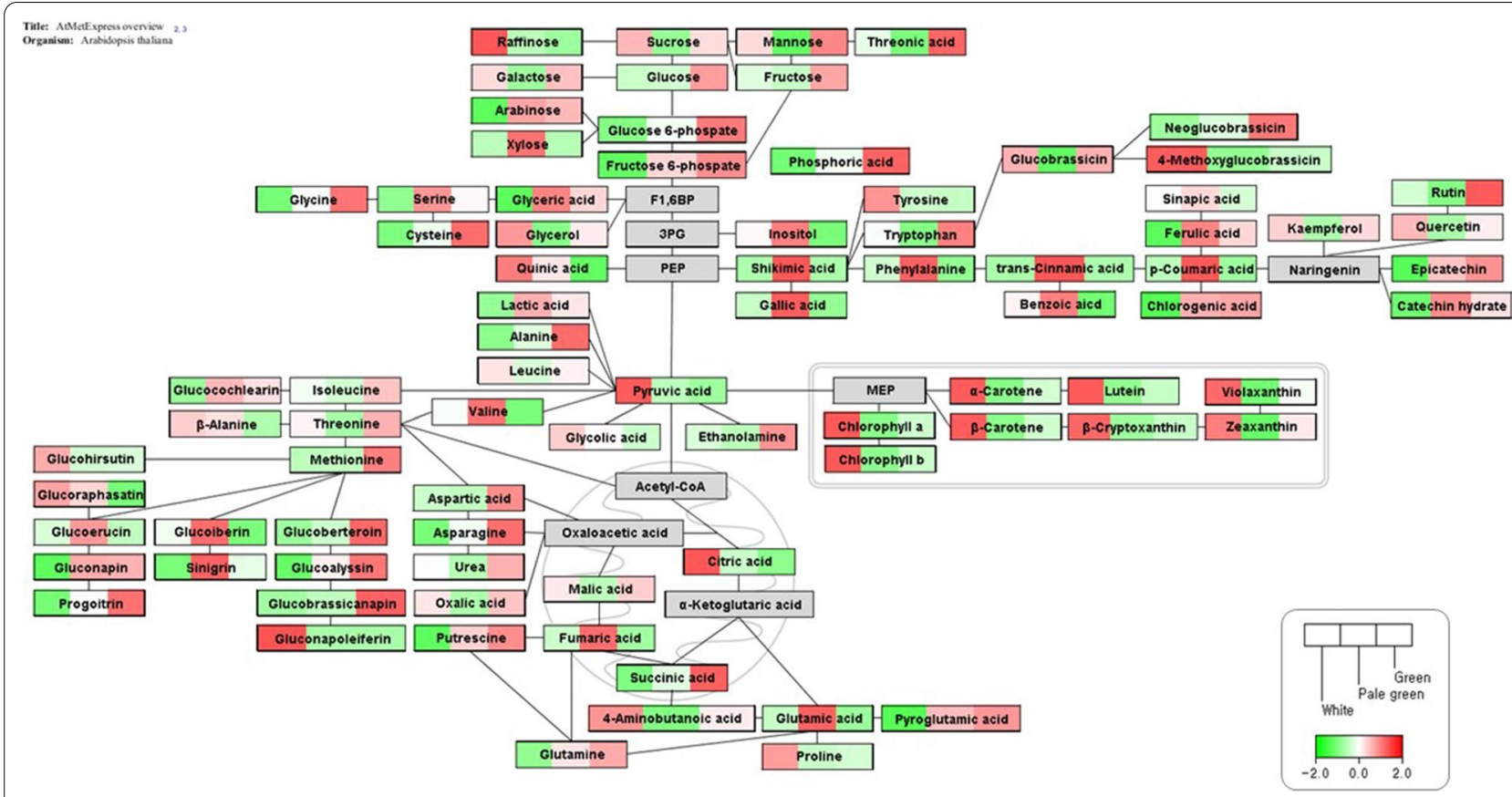

Fig. 6 Metabolite pathway map comparing primary and secondary metabolites in the white, pale green, and green pak choi cultivars. The unit variance scaling data are represented by the intensity of the green and red color as shown in the bottom right box. The gray boxes represent the metabolites that were not be detected. F1,6BP, fructose 1,6-bisphosphate; 3PG, 3-phosphoglycerate; PEP, 2-phosphoenolpyruvate; MEP, methylerythritol 4-phosphate

measures. A correlation analysis enables understanding relationships between metabolites in a biological system [33]. To understand the correlation between 85 metabolites in the three pak choi cultivars, HCA with Pearson's correlation coefficient was performed. As a result of $\mathrm{HCA}$, the metabolite-to-metabolite correlation matrix was obtained (Fig. 7 and Additional file 2: Table S4). The metabolites that were associated with closely related biosynthetic pathway were clustered in major two groups (boxed within yellow dotted lines). One group contained phenolic acids and flavanols and it was positively correlated with each other. Sinapic acid was also positively correlated with other phenolic acids although it was contained the other group. In addition, phenylalanine and shikimic acid were positively correlated with transcinnamic acid, $p$-coumaric acid, ferulic acid, sinapic acid, benzoic acid, and chlorogenic acid. Those metabolites share phenylalanine as an intermediate and shikimic acid is a precursor of phenylalanine. The other group was divided another two groups (boxed within green lines). Photosynthetic pigments were clustered together in one group and flavonols were clustered together in the other group. The pigments and flavonols were positively correlated in each group. A positive correlation was found between pyruvic acid and pigments. In addition, a negative correlation was found between pyruvic acid and sugars (glucose, fructose, glucose 6-phosphate, and fructose 6-phosphate). Notably, significant negative correlations were observed between pigments and phenylpropanoids except for flavonols. For example, significant positive correlations were observed between $\beta$-carotene and ferulic acid $(r=-0.9687, p<0.0001)$, chlorogenic acid $(r=-0.9313, p=0.0002)$, catechin $(r=-0.9208$, $p=0.0004)$, and epicatechin $(r=-0.8858, p=0.0022)$.

\section{Discussion}

In the present study, we characterized most secondary metabolites in pak choi cultivars of different colors. Phenolic compounds, carotenoids, and glucosinolates play crucial roles in plant defense mechanisms and have potential benefits for human health [34-36]. We found that the levels of phenolic compounds, carotenoids, chlorophyll, and glucosinolates differed significantly between the three pak choi cultivars. A similar result was obtained when analyzing the glucosinolate profiles of 13 different pak choi sprouts (B. rapa ssp. chinensis), in which the individual glucosinolate concentration differed significantly [37]. A recent study identified 13 glucosinolates from 11 varieties of Chinese cabbage. Those authors found that the levels of glucosinolates and carotenoids differed significantly between different varieties of Chinese cabbage [9, 38]. Kim et al. [39] reported that 


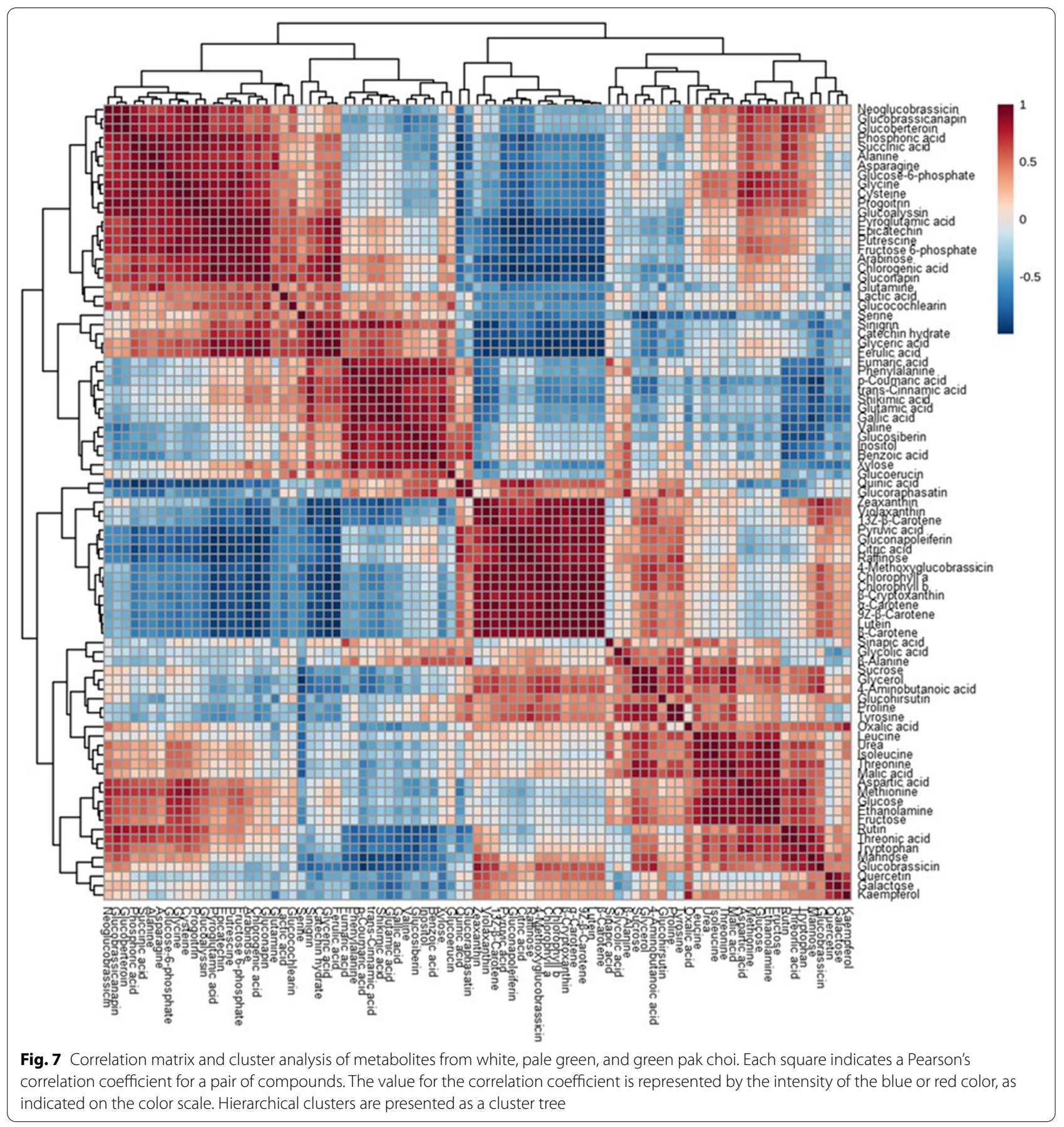

Chinese cabbage cultivars, such as e-Norange, Kori, and Sandun, are suitable for breeding programs due to their high levels of glucosinolates. Recently, metabolic profiling of rectangular and oval Chinese cabbage cultivars identified eight individual glucosinolate compounds, whose contents varied significantly between cultivars [9]. In addition, metabolic profiling of nine Chinese cabbage cultivars revealed variation in the content of glucosinolates and carotenoids. Among those different cultivars, the Cheonsangcheonha and Waldong-cheonha cultivars presented the highest total glucosinolates and carotenoid levels [40]. Analysis of the carotenoid composition of two Chinese cabbage cultivars $B$. rapa 'orange queen' and $B$. rapa 'Yuki', revealed significant variation in the composition of major carotenoids and the contents of total carotenoids [41]. 
Most studies have reported significant variation in the accumulation and content of phenolic compounds in different pak choi and Chinese cabbage cultivars, which is similar to the results of the present study [9, 27, 41-43]. Analysis of phenylpropanoid contents in mature leaves of the green pak choi cultivar ' 8210 ' and the purple cultivar ' 8389 ' revealed significant variation between cultivars [27]. Jiang et al. [42] compared $B$. rapa 'Shinhong Ssam' (red) and B. rapa 'Samjin' (green) Chinese cabbage cultivars and reported significant differences in the level of phenols. Among those two cultivars, the red cultivar presented the highest levels of caffeic acid, ferulic acid, isorhamnetin, kaempferol, $p$-coumaric acid, quercetin, and sinapic acid. Similarly, in another study, analysis of variation in the phenolic compounds of Chinese cabbage cultivars $B$. rapa 'Kwonnongbbalgang No. 2' (red) and B. rapa 'Bulam' No. 3, B. rapa 'Hwangsim', and B. rapa 'CR-power' (green), revealed significant differences in the accumulation of phenolic compounds [43]. The difference in the accumulation of secondary metabolites might be caused by many factors [15], such as the chemical analysis conditions [44], climatic factors [45], developmental and environmental regulation [46], species specificity [47], and variety specificity [48, 49]. These factors might affect the quality and quantity of secondary metabolites in plants.

Phenylalanine is a common precursor for the synthesis of various phenylpropanoid compounds. Indolic glucosinate biosynthesis has been reported to limit the accumulation of phenylpropanoid in Arabidopsis thaliana [50]. However, this does not occur in pak choi cultivars; in the present study, all three pak choi cultivars accumulated glucosinolate at low levels, whereas the phenylpropanoid content was increased. A previous study using Vitis suspension culture showed the endogenous phenylalanine content increased at the end of cell division. This might lead to increased expression of phenylalanine ammonialyase (PAL) and chalcone synthase (CHS) and subsequent increase in the activity of these two enzymes, leading to over-accumulation of anthocyanin content [51]. In addition, the application of exogenous phenylalanine was found to enhance CHS expression and anthocyanin accumulation when Vitis suspension culture contained low levels of endogenous phenylalanine during cell division. Moreover, the use of transgenic tobacco revealed that overexpression of $P A L$, which is involved in the conversion of phenylalanine to cinnamic acid, resulted in a greater accumulation of phenylpropanoid content [52]. Similarly, other phenylpropanoid pathway genes, such as cinnamate 4-hydroxylase $(\mathrm{C} 4 \mathrm{H})$ and chalcone isomerase $(\mathrm{CHI})$, are significantly associated with phenylpropanoid accumulation [53, 54].
Jeon et al. [27] reported less accumulation of phenylpropanoid in the green pak choi cultivar compared with the purple pak choi cultivar ' 8389 '. In addition, only seven phenylpropanoids were found in the green pak choi cultivar ' 8210 ', in which quercetin and kaempferol were not detected [27]. However, in the present study, 11 phenylpropanoids were identified in each of the three pak choi cultivars, with the highest accumulation observed in green pak choi. The phenylpropanoid content in the green pak choi used in this study was higher than that in the green pak choi cultivar ' 8210 .

The results of in vitro antioxidant activity assays revealed a slight increase in reducing DPPH free radical scavenging activity, and in the reducing powers assay in the green and pale green cultivars. This was consistent with the results of a previous study, which demonstrated that phenolic compounds can exert antioxidant activity via numerous pathways [55]. Free radical scavenging might be important, in which the phenolic molecule can be degraded in the free radical chain reaction [56]. The presence of various substituents in the phenol backbone might regulate their antioxidant activity, especially, their hydrogen-donating capability. This was similar to our results; the green and pale green pak choi cultivars accumulated the highest amount of total phenolic compounds, leading to increased antioxidant activities (such as DPPH free radical scavenging activity and reducing powers assay) in both cultivars.

Metabolic profiling and chemometrics have been used to analyze metabolic interactions in Brassicaceae vegetables $[9,40,57]$. A negative relationship between anthocyanins and primary metabolites was observed in purple kohlrabi [58]. A correlation between the metabolites was observed in those that participated in closely related pathways in colored cauliflowers [59]. As shown in previous studies, using the metabolic pathway map and HCA, it was revealed that metabolites were likely to be correlated with other metabolites with shared metabolism in pak choi, although the content and composition of individual metabolites differed between cultivars. The white cultivar contained the highest levels of pyruvic acid, chlorophylls, and carotenoids. In contrast, intermediates of glycolysis (glucose 6-phosphate, and fructose 6-phosphate) were present at lower levels in the white cultivar than in the other cultivars. Pyruvic acid positively correlated with pigments and negatively correlated with sugars (glucose, fructose, glucose 6-phosphate, and fructose 6-phosphate). This indicated that glucose was rapidly converted to pyruvic acid via glycolysis, and that activation of the methylerythritol 4-phosphate (MEP) pathway was enhanced, leading to the production of pigments in the white cultivar. The pale green pak choi contained higher levels of phenolic acids and flavonols. In addition, 
the levels of phenylalanine, which is used for phenylpropanoid metabolism, and shikimic acid, which is used for phenylalanine metabolism, were higher in the pale green pak choi than in the other cultivars. A positive correlation between phenolic acids and flavonols has been reported in cabbage [60], but a negative correlation was detected in the three pak choi cultivars. In transgenic tobacco, the overexpression of $P A L$, which is involved in the conversion of phenylalanine to cinnamic acid, resulted in a higher accumulation of phenylpropanoid content [52]. This indicated that the phenylpropanoid pathway was more active in the pale green cultivar for accumulating flavanols than in the other cultivars. In the green cultivar, the levels of precursors (methionine, and tryptophan) for glucosinolates and total glucosinolate were highest among the three cultivars. In broccoli, there was no significant correlation between free amino acids (methionine, tryptophan, and phenylalanine) and glucosinolates [61]. In rapeseed, protein, methionine, and glucosinolate content were reduced at low sulfate levels [62]. In the case of green pak choi a positive relationship was found between amino acids (methionine, tryptophan) and some glucosinolates.

In this study, we explored the metabolic profiles of primary and secondary metabolites in three pak choi cultivars of different colors. The results confirmed that HPLC and GC-TOFMS-based metabolite profiling are suitable techniques for identifying the difference between metabolites in pak choi cultivars. Forty-nine metabolites (22 amino acids and amino acid derivatives, 13 organic acids, inorganic acids, organic compounds, and 14 sugars, sugar alcohols), eleven phenolics, fifteen glucosinolates, and eight carotenoid compounds were identified and quantified. The pale green and green cultivars showed the highest accumulation of total phenolics and glucosinolate content, whereas the levels of carotenoid and chlorophyll content were higher in the white cultivar. In the white, pale green, and green cultivars, SOD activity, DPPH free radical scavenging activity, and reducing power were slightly increased, respectively. The results showed that pak choi extracts possess antioxidant properties. In addition, a negative correlation between pigments (carotenoids and chlorophylls) and phenylpropanoids (phenolic acids and flavanols) was revealed using metabolite-to-metabolite correlation analysis. This appears to be the first such observation of relationships between photosynthetic pigments and phenylpropanoids in pak choi. The results of metabolic profiling will provide knowledge on the phenolics, glucosinolates, carotenoids, chlorophyll contents, and antioxidant activity in different-colored pak choi cultivars, and is useful information for the human consumption of this leaf vegetables. Moreover, this information might be helpful to improve the content of different phytochemicals, such as phenolics, glucosinolates, carotenoids, and chlorophyll in pak choi cultivars. Furthermore, analyzation of the relationship between metabolites might provide for understanding the secondary metabolite biosynthetic pathway of pak choi. In addition, this study may provide support for a synergetic antioxidant, which is derived from phenylpropanoids, glucosinolates, carotenoids, and chlorophyll in the leaves of pak choi cultivars.

\section{Supplementary Information}

The online version contains supplementary material available at https://doi. org/10.1186/s13765-020-00574-2.

Additional file 1: Fig. S1. GC-TOFMS chromatogram of hydrophilic compounds in the pale green pak choi. Peak: 1, Pyruvic acid; 2, Lactic acid; 3, Alanine; 4, Oxalic acid; 5, Glycolic acid, 6, Valine; 7. Urea; 8, Serine-1; 9, Ethanolamine; 10, Glycerol; 11, Phosphoric acid; 12 , Leucine; 13, Isoleucine; 14, Proline; 15, Glycine; 16, Succinic acid; 17, Glyceric acid; 18, Fumaric acid; 19, Serine-2; 20, Threonine; 21, $\beta$-Alanine; 22, Malic acid; 23, Aspartic acid; 24, Methionine; 25, Pyroglutamic acid; 26, 4-Aminobutanoic acid: 27, Threonic acid; 28, Cysteine; 29, Glutamic acid; 30, Phenylalanine; 31 , Xylose-1; 32, Xylose-2; 33, Arabinose; 34, Asparagine; 35, Adonitol (Internal standard); 36, Putrescine; 37, Glutamine; 38, Shikimic acid; 39, Citric Acid; 40, Quinic acid; 41, Fructose-1; 42, Fructose-2; 43, Mannose; 44, Galactose; 45, Glucose-1; 46, Glucose-2; 47, Tyrosine; 48, Inositol; 49, Tryptophan; 50, Sinapic acid; 51, Fructose-6-phosphate; 52, Glucose-6-phosphate-1; 53, Glucose-6-phosphate-2; 54, Sucrose; 55, Raffinose. Fig. S2. HPLC chromatogram of phenylpropanoids in the pale green pak choi. Peak: 1, Gallic acid; 2, Catechin hydrate; 3, Chlorogenic acid; 4, Epicatechin; 5, p-coumaric acid; 6, Ferulic acid; 7, Benzoic acid; 8, Rutin; 9, trans-Cinnamic acid; 10, Quercetin; 11, Kaempferol. Fig. S3. HPLC chromatogram of carotenoids in pale green pak choi. Peak: 1, Violaxanthin; 2, Lutein; 3 , Zeaxanthin; 4, $\beta$-apo-8'-carotenal (Internal standard); 5, $\beta$-cryptoxanthin; 6, 13Z- $\beta$-carotene; 7, a-carotene; 8, $\beta$-carotene; 9, 9Z- $\beta$-carotene. Fig. S4. HPLC chromatogram of glucosinolates in the pale green pakchoi. Peak: 1, Progoitrin; 2, Sinigrin; 3, Glucoalyssin; 4, Gluconapin; 5, Glucoiberin; 6, Glucobrassicanapin; 7, Glucoerucin; 8, Glucoraphasatin; 9, Glucobrassicin; 10, 4-Methoxyglucobrassicin; 11, Glucoberteroin; 12, Neoglucobrassicin. Table S1. Dry weight of whole plant of white, pale green, and green pak choi. Table S2. Variable importance in the projection (VIP) was obtained from the partial least squares-discriminant analysis (PLS-DA) model with VIP > 1.0. Table S3. Hydrophilic metabolites contents in white, pale green, and green pak choi.

Additional file 2: Table S4. Pearson's correlation analysis of metabolite data obtained from the white, pale green, and green pak choi.

\section{Abbreviations}

$\mathrm{C} 4 \mathrm{H}$ : Cinnamate 4-hydroxylase; $\mathrm{CHI}$ : Chalcone isomerase; $\mathrm{CHS}$ : Chalcone synthase; DEAE: Diethylaminoethanol; DPPH: 2,2-Diphenyl-1-picrylhydrazyl; EDTA: Ethylenediaminetetraacetic acid; GC-TOFMS: Gas chromatography attached with time-of-flight mass spectrometry; HCA: Hierarchical cluster analysis; HPLC: High-performance liquid chromatography; MEP: Methylerythritol 4-phosphate; NBT: Nitroblue tetrazolium; PAL: Phenylalanine ammonialyase; PC1: Principal component 1; PCA: Principal component analysis; PLS-DA: Partial least squares-discriminant analysis; SOD: Superoxide dismutase; TCA: Trichloroacetic acid; UV: Unit variance.

\section{Authors' contributions}

JKK and SUP conceived and designed the experimental work. HJY, SAB, and RS carried out the experiments. RS, JKK, and SUP wrote the manuscript. All authors read and approved the final manuscript. 


\section{Funding}

This research was supported by Golden Seed Project (213006051WTE11) funded by Ministry of Agriculture, Food and Rural Affairs (MAFRA), Ministry of Oceans and Fisheries (MOF), Rural Development Administration (RDA) and Korea Forest Service (KFS), Republic of Korea.

\section{Availability of data and materials}

All data generated or analyzed during this study are included in this published article and its Additional file 1.

\section{Ethics approval and consent to participate}

Not applicable because we did not work with animals or humans.

\section{Competing interests}

The authors declare that they have no competing interests.

\section{Author details}

${ }^{1}$ Department of Crop Science, Chungnam National University, 99 Daehak-ro, Yuseong-gu, Daejeon 34134, Republic of Korea. ${ }^{2}$ Division of Life Sciences and Bio-Resource and Environmental Center, Incheon National University, Yeonsu-gu, Incheon 22012, Republic of Korea. ${ }^{3}$ Department of Smart Agriculture Systems, Chungnam National University, 99 Daehak-ro, Yuseong-gu, Daejeon 34134, Republic of Korea.

Received: 27 June 2020 Accepted: 2 December 2020

Published online: 09 January 2021

\section{References}

1. Biala W, Jasinski M (2018) The phenylpropanoid case - It is transport that matters. Front Plant Sci 9:1610. https://doi.org/10.3389/fpls.2018.01610

2. Cevallos-Casals BA, Cisneros-Zevallos $L$ (2010) Impact of germination on phenolic content and antioxidant activity of 13 edible seed species. Food Chem 119:1485-1490. https://doi.org/10.1016/j.foodchem.2009.09.030

3. Korkina L, Kostyuk V, De Luca C, Pastore S (2011) Plant phenylpropanoids as emerging anti-inflammatory agents. Mini-Rev Med Chem 11:823-835. https://doi.org/10.2174/138955711796575489

4. Panda P, Appalashetti M, Judeh ZMA (2011) Phenylpropanoid sucrose esters: Plant-derived natural products as potential leads for new therapeutics. Curr Med Chem 18:3234-3251. https://doi.org/10.2174/09298 6711796391589

5. Yang CS, Landau JM, Huang MT, Newmark HL (2001) Inhibition of carcinogenesis by dietary polyphenolic compounds. Annu Rev Nutr 21:381-406. https://doi.org/10.1146/annurev.nutr.21.1.381

6. Yao LH, Jiang YM, Shi J, Tomas-Barberan FA, Datta N, Singanusong R, Chen SS (2004) Flavonoids in food and their health benefits. Plant Food Hum Nutr 59:113-122. https://doi.org/10.1007/s11130-004-0049-7

7. Sathasivam R, Ki JS (2018) A review of the biological activities of microalgal carotenoids and their potential use in healthcare and cosmetic industries. Mar Drugs 16:26. https://doi.org/10.3390/md16010026

8. Sathasivam R, Ki JS (2019) Differential transcriptional responses of carotenoid biosynthesis genes in the marine green alga Tetraselmis suecica exposed to redox and non-redox active metals. Mol Biol Rep 46:11671179. https://doi.org/10.1007/s11033-018-04583-9

9. Park CH, Yeo HJ, Park SY, Kim JK, Park SU (2019) Comparative phytochemical analyses and metabolic profiling of different phenotypes of Chinese cabbage (Brassica rapa ssp. pekinensis). Foods 8:587. https://doi. org/10.3390/foods8110587

10. Sathasivam R, Radhakrishnan R, Kim JK, Park SU (2020) An update on biosynthesis and regulation of carotenoids in plants. S Afr J Bot. https:// doi.org/10.1016/j.sajb.2020.05.015

11. Wang YT, Yang CH, Huang TY, Tai MH, Sie RH, Shaw JF (2019) Cytotoxic effects of chlorophyllides in ethanol crude extracts from plant leaves. Evid-Based Compl Alt 9494328:13. https://doi.org/10.1155/2019/9494328

12. Zhu B, Yang J, Zhu ZJ (2013) Variation in glucosinolates in pak choi cultivars and various organs at different stages of vegetative growth during the harvest period. J Zhejiang Univ-Sc B 14:309-317. https://doi. org/10.1631/jzus.B1200213
13. Barba FJ, Nikmaram N, Roohinejad S, Khelfa A, Zhu ZZ, Koubaa M (2016) Bioavailability of glucosinolates and their breakdown products: impact of processing. Front Nutr 3:24. https://doi.org/10.3389/fnut.2016.00024

14. Padilla G, Cartea ME, Velasco P, de Haro A, Ordas A (2007) Variation of glucosinolates in vegetable crops of Brassica rapa. Phytochemistry 68:536-545. https://doi.org/10.1016/j.phytochem.2006.11.017

15. Park CH, Yeo HJ, Baskar TB, Park YE, Park JS, Lee SY, Park SU (2019) In vitro antioxidant and antimicrobial properties of flower, leaf, and stem extracts of Korean mint. Antioxidants-Basel 8:75. https://doi.org/10.3390/antio x8030075

16. Mates JM, Perez-Gomez C, De Castro IN (1999) Antioxidant enzymes and human diseases. Clin Biochem 32:595-603. https://doi.org/10.1016/ S0009-9120(99)00075-2

17. Garcia-Andrade M, Gonzalez-Laredo RF, Rocha-Guzman NE, GallegosInfante JA, Rosales-Castro M, Medina-Torres L (2013) Mesquite leaves (Prosopis laevigata), a natural resource with antioxidant capacity and cardioprotection potential. Ind Crop Prod 44:336-342. https://doi. org/10.1016/j.indcrop.2012.11.030

18. Giliberto L, Perrotta G, Pallara P, Weller JL, Fraser PD, Bramley PM, Fiore A, Tavazza M, Giuliano G (2005) Manipulation of the blue light photoreceptor cryptochrome 2 in tomato affects vegetative development, flowering time, and fruit antioxidant content. Plant Physiol 137:199-208. https://doi. org/10.1104/pp.104.051987

19. Schofield A, Paliyath G (2005) Modulation of carotenoid biosynthesis during tomato fruit ripening through phytochrome regulation of phytoene synthase activity. Plant Physiol Bioch 43:1052-1060. https://doi. org/10.1016/j.plaphy.2005.10.006

20. vonLintig J, Welsch R, Bonk M, Giuliano G, Batschauer A, Kleinig H (1997) Light-dependent regulation of carotenoid biosynthesis occurs at the level of phytoene synthase expression and is mediated by phytochrome in Sinapis alba and Arabidopsis thaliana seedlings. Plant J 12:625-634. https://doi.org/10.1046/j.1365-313X.1997.d01-16.x

21. Woitsch S, Romer S (2003) Expression of xanthophyll biosynthetic genes during light-dependent chloroplast differentiation. Plant Physiol 132:1508-1517. https://doi.org/10.1104/pp.102.019364

22. Zhang YJ, Chen GP, Dong TT, Pan Y, Zhao ZP, Tian SB, Hu ZL (2014) Anthocyanin accumulation and transcriptional regulation of anthocyanin biosynthesis in purple bok-choy (Brassica rapa var. Chinensis). J Agr Food Chem 62:12366-12376. https://doi.org/10.1021/jf503453e

23. Bhandari SR, Jo JS, Lee JG (2015) Comparison of glucosinolate profiles in different tissues of nine Brassica crops. Molecules 20:15827-15841. https ://doi.org/10.3390/molecules200915827

24. Harbaum B, Hubbermann EM, Wolff C, Herges R, Zhu Z, Schwarz K (2007) Identification of flavonoids and hydroxycinnamic acids in pak choi varieties (Brassica campestris L. ssp. chinensis var. communis) by HPLC-ESI-MSn and NMR and their quantification by HPLC-DAD. J Agric Food Chem 55:8251-8260. https://doi.org/10.1021/jf071314+

25. Harbaum B, Hubbermann EM, Zhu ZJ, Schwarz K (2008) Free and bound phenolic compounds in leaves of pak choi (Brassica campestris L. Ssp chinensis var. communis) and Chinese leaf mustard (Brassica juncea Coss). Food Chem 110:838-846. https://doi.org/10.1016/j.foodc hem.2008.02.069

26. Rochfort SJ, Imsic M, Jones R, Trenerry VC, Tomkins B (2006) Characterization of flavonol conjugates in immature leaves of pak choi [Brassica rapa L. Ssp chinensis L. (Hanelt.)] by HPLC-DAD and LC-MS/MS. J Agr Food Chem 54:4855-4860. https://doi.org/10.1021/jf060154j

27. Jeon J, Lim CJ, Kim JK, Park SU (2018) Comparative metabolic profiling of green and purple pakchoi (Brassica Rapa Subsp Chinensis). Molecules 23:613. https://doi.org/10.3390/molecules23071613

28. Park CH, Yeo HJ, Park YE, Baek SA, Kim JK, Park SU (2019) Transcriptome analysis and metabolic profiling of Lycoris radiata. Biology-Basel 8:63. https://doi.org/10.3390/biology8030063

29. Ha SH, Kim JK, Jeong YS, You MK, Lim SH, Kim JK (2019) Stepwise pathway engineering to the biosynthesis of zeaxanthin, astaxanthin and capsanthin in rice endosperm. Metab Eng 52:178-189. https://doi.org/10.1016/j. ymben.2018.11.012

30. Wellburn AR (1994) The spectral determination of chlorophyll-a and chlorophhyll-B, as well as total carotenoids, using various solvents with spectrophotometers of different resolution. J Plant Physiol 144:307-313. https://doi.org/10.1016/S0176-1617(11)81192-2 
31. Jeon J, Kim JK, Wu Q, Park SU (2018) Effects of cold stress on transcripts and metabolites in tartary buckwheat (Fagopyrum tataricum). Environ Exp Bot 155:488-496. https://doi.org/10.1016/j.envexpbot.2018.07.027

32. Kutmon M, van lersel MP, Bohler A, Kelder T, Nunes N, Pico AR, Evelo CT (2015) PathVisio 3: An extendable pathway analysis toolbox. PLOS Comput Biol 11:e1004085. https://doi.org/10.1371/journal.pcbi.1004085

33. Steuer R, Kurths J, Fiehn O, Weckwerth W (2003) Interpreting correlations in metabolomic networks. Biochem Soc T 31:1476-1478. https://doi. org/10.1042/bst0311476

34. Cuong D, Ha TW, Park CH, Kim NS, Yeo HJ, Chun SW, Kim C, Park SU (2019) Effects of LED lights on expression of genes involved in phenylpropanoid biosynthesis and accumulation of phenylpropanoids in wheat sprout. Agronomy-Basel 9:307. https://doi.org/10.3390/agronomy9060307

35. Cuong D, Park SU, Park CH, Kim NS, Bong SJ, Lee SY (2019) Comparative analysis of glucosinolate production in hairy roots of green and red kale (Brassica oleracea var. acephala). Prep Biochem Biotech 49:775-782. https ://doi.org/10.1080/10826068.2019.1615505

36. Tuan PA, Lee J, Park CH, Kim JK, Noh YH, Kim YB, Kim H, Park SU (2019) Carotenoid biosynthesis in oriental melon (Cucumis melo L. var. makuwa). Foods 8:77. https://doi.org/10.3390/foods8020077

37. Wiesner M, Zrenner R, Krumbein A, Glatt H, Schreiner M (2013) Genotypic variation of the glucosinolate profile in pak choi (Brassica rapa ssp chinensis). J Agr Food Chem 61:1943-1953. https://doi.org/10.1021/jf303970k

38. Chun JH, Kim NH, Seo MS, Jin M, Park SU, Arasu MV, Kim SJ, Al-Dhabi NA (2018) Molecular characterization of glucosinolates and carotenoid biosynthetic genes in Chinese cabbage (Brassica rapa L. ssp pekinensis). Saudi J Biol Sci 25:71-82. https://doi.org/10.1016/j.sjbs.2016.04.004

39. Kim JK, Chu SM, Kim SJ, Lee DJ, Lee SY, Lim SH, Ha SH, Kweon SJ, Cho HS (2010) Variation of glucosinolates in vegetable crops of Brassica rapa L. ssp pekinensis. Food Chem 119:423-428. https://doi.org/10.1016/j.foodc hem.2009.08.051

40. Baek SA, Jung YH, Lim SH, Park SU, Kim JK (2016) Metabolic profiling in Chinese cabbage (Brassica rapa L. subsp pekinensis) cultivars reveals that glucosinolate content is correlated with carotenoid content. J Agr Food Chem 64:4426-4434. https://doi.org/10.1021/acs.jafc.6b01323

41. Watanabe M, Musumi K, Ayugase J (2011) Carotenoid pigment composition, polyphenol content, and antioxidant activities of extracts from orange-colored Chinese cabbage. LWT-Food Sci Technol 44:1971-1975. https://doi.org/10.1016/j.lwt.2011.04.010

42. Jiang N, Chung SO, Lee J, Ryu D, Lim YP, Park S, Lee C, Song J, Kim K, Park JT, An G (2013) Increase of phenolic compounds in new Chinese cabbage cultivar with red phenotype. Hortic Environ Biote 54:82-88. https://doi. org/10.1007/s13580-013-0136-5

43. Lee H, Oh IN, Kim J, Jung DH, Cuong NP, Kim Y, Lee J, Kwon O, Park SU, Lim Y, Kim B, Park JT (2018) Phenolic compound profiles and their seasonal variations in new red phenotype head-forming Chinese cabbages. LWTFood Sci Technol 90:433-439. https://doi.org/10.1016/j.lwt.2017.12.056

44. Markom M, Hasan M, Daud WRW, Singh H, Jahim JM (2007) Extraction of hydrolysable tannins from Phyllanthus niruri Linn.: Effects of solvents and extraction methods. Sep Purif Technol 52:487-496. https://doi. org/10.1016/j.seppur.2006.06.003

45. Guo LP, Wang S, Zhang J, Yang G, Zhao MX, Ma WF, Zhang XB, Li X, Han BX, Chen N, Huang LQ (2013) Effects of ecological factors on secondary metabolites and inorganic elements of Scutellaria baicalensis and analysis of geoherblism. Sci China Life Sci 56:1047-1056. https://doi.org/10.1007/ s11427-013-4562-5

46. Szakiel A, Paczkowski C, Henry M (2011) Influence of environmental abiotic factors on the content of saponins in plants. Phytochem Rev 10:471-491. https://doi.org/10.1007/s11101-010-9177-x

47. Park CH, Park SY, Lee SY, Kim JK, Park SU (2018) Analysis of metabolites in white flowers of Magnolia denudata Desr. and violet flowers of Magnolia liliiflora Desr. Molecules 23:1558. https://doi.org/10.3390/molecules2 3071558

48. Zhao SC, Park CH, Yang JL, Yeo HJ, Kim TJ, Kim JK, Park SU (2019) Molecular characterization of anthocyanin and betulinic acid biosynthesis in red and white mulberry fruits using high-throughput sequencing. Food Chem 279:364-372. https://doi.org/10.1016/j.foodchem.2018.11.101

49. Park CH, Morgan AMA, Park BB, Lee SY, Lee S, Kim JK, Park SU (2019) Metabolic analysis of four cultivars of Liriope platyphylla. Metabolites 9:59. https://doi.org/10.3390/metabo9030059

50. Kim JI, Dolan WL, Anderson NA, Chapple C (2015) Indole glucosinolate biosynthesis limits phenylpropanoid accumulation in Arabidopsis thaliana. Plant Cell 27:1529-1546. https://doi.org/10.1105/tpc.15.00127

51. Sakuta M, Hirano H, Kakegawa K, Suda J, Hirose M, Joy RW, Sugiyama M, Komamine A (1994) Regulatory mechanisms of biosynthesis of betacyanin and anthocyanin in relation to cell-division activity in suspensioncultures. Plant Cell Tiss Org 38:167-169. https://doi.org/10.1007/Bf000 33874

52. Howles PA, Sewalt VJH, Paiva NL, Elkind Y, Bate NJ, Lamb C, Dixon RA (1996) Overexpression of L-phenylalanine ammonia-lyase in transgenic tobacco plants reveals control points for flux into phenylpropanoid biosynthesis. Plant Physiol 112:1617-1624. https://doi.org/10.1104/ pp.112.4.1617

53. Blount JW, Korth KL, Masoud SA, Rasmussen S, Lamb C, Dixon RA (2000) Altering expression of cinnamic acid 4-hydroxylase in transgenic plants provides evidence for a feedback loop at the entry point into the phenylpropanoid pathway. Plant Physiol 122:107-116. https://doi.org/10.1104/ pp.122.1.107

54. Muir SR, Collins GJ, Robinson S, Hughes S, Bovy A, De Vos CHR, van Tunen AJ, Verhoeyen ME (2001) Overexpression of petunia chalcone isomerase in tomato results in fruit containing increased levels of flavonols. Nat Biotechnol 19:470-474. https://doi.org/10.1038/88150

55. Briante R, Febbraio F, Nucci R (2003) Antioxidant properties of low molecular weight phenols present in the Mediterranean diet. J Agr Food Chem 51:6975-6981. https://doi.org/10.1021/jf034471r

56. Lee OH, Lee BY (2010) Antioxidant and antimicrobial activities of individual and combined phenolics in Olea europaea leaf extract. Bioresource Technol 101:3751-3754. https://doi.org/10.1016/j.biortech.2009.12.052

57. Lee KB, Kim YJ, Kim HJ, Choi J, Kim JK (2018) Phytochemical profiles of Brassicaceae vegetables and their multivariate characterization using chemometrics. Appl Biol Chem 61:131-144. https://doi.org/10.1007/ s13765-017-0340-6

58. Park CH, Yeo HJ, Kim NS, Eun PY, Kim SJ, Arasu MV, Al-Dhabi NA, Park SY, Kim JK, Park SU (2017) Metabolic profiling of pale green and purple kohlrabi (Brassica oleracea var. gongylodes). Appl Biol Chem 60:249-257. https://doi.org/10.1007/s13765-017-0274-z

59. Park SY, Lim SH, Ha SH, Yeo Y, Park WT, Kwon DY, Park SU, Kim JK (2013) Metabolite profiling approach reveals the interface of primary and secondary metabolism in colored cauliflowers (Brassica oleracea L. ssp botrytis). J Agr Food Chem 61:6999-7007. https://doi.org/10.1021/jf401 330e

60. Park S, Arasu MV, Jiang N, Choi SH, Lim YP, Park JT, Al-Dhabi NA, Kim SJ (2014) Metabolite profiling of phenolics, anthocyanins and flavonols in cabbage (Brassica oleracea var. capitata). Ind Crop Prod 60:8-14. https:// doi.org/10.1016/j.indcrop.2014.05.037

61. Rosa E, Gomes MH (2002) Relationship between free amino acids and glucosinolates in primary and secondary inflorescences of 11 broccoli (Brassica oleracea $\mathrm{L}$ var italica) cultivars grown in early and late seasons. J Sci Food Agr 82:61-64. https://doi.org/10.1002/jsfa.999

62. Josefsson E (1970) Glucosinolate content and amino acid composition of rapeseed (Brassica napus) meal as affected by sulphur and nitrogen nutrition. J Sci Food Agr 21:98-103. https://doi.org/10.1002/jsfa.2740210211

\section{Publisher's Note}

Springer Nature remains neutral with regard to jurisdictional claims in published maps and institutional affiliations. 